\title{
Rheology of two-phase systems: A microphysical and observational approach
}

\author{
John P. Platt* \\ Department of Earth Sciences, University of Southern California, Los Angeles, \\ California, 90089-0742, USA \\ jplatt@usc.edu \\ *corresponding author. phone: +1-213-821-1194.
}

\section{Keywords}

shear zone; rheology; polyphase; microstructure 


\section{Abstract}

2 Ductile shear zones commonly contain distinctive bands of high strain rock characterized

3 by intimately mixed fine-grained two-phase or polyphase material. These ultramylonite

4 bands are weaker than the surrounding material, and may play a critical role in strain

5 localization. How such zones develop, how the phases become evenly dispersed, the bulk

6 rheology, and the controls on grain size, are all unclear. The following generic scenario

7 may resolve some of these questions.

8 1) Dislocation creep and dynamic recrystallization cause grain-size reduction: commonly,

9 the recrystallized grain sizes of the two phases differ.

10 2) Grain size reduction causes a switch to grain-boundary diffusion creep, which requires

11 grain-boundary sliding. Diffusion allows one phase to fill spaces that open between

12 grains of the other: this will happen most rapidly in the finer-grained phase. The grain

13 size of the resulting mixture is therefore controlled by that of the finer-grained phase.

14 This leads to mixing and dispersion of the two phases, producing a fine-grained, evenly

15 dispersed two-phase aggregate.

16 4) The bulk rheology will be controlled by grain-boundary diffusion creep of the two

17 phases, with the grain-size controlled by the finer-grained phase.

18 Bulk flow laws can be developed for quartz-feldspar and olivine-orthopyroxene

19 ultramylonites based on these concepts, using appropriate mixing laws.

\section{1. Introduction}

22 Much of our understanding of the rheology of rocks deformed in the ductile regime

23 comes from experimental data on single-phase materials, such as quartz, feldspar, calcite, 
24 and olivine. It is now widely recognized that strain localization in crystalline materials is

25 largely a result of microstructural changes consequent upon deformation, including grain-

26 size reduction (e.g., Schmid, 1982; Rutter and Brodie, 1988; Braun et al., 1999), and the

27 development of crystallographic preferred orientation (CPO) (e.g., Muto et al., 2011).

28 The dominant rock-types in the lithosphere are polyphase, however, and the bulk

29 mechanical properties of these materials are likely to be different from those of the

30 individual minerals. A common observation is that polyphase materials form

31 ultramylonite bands within which the phases are finely and intimately mixed, and that

32 these fine-grained mixtures are significantly weaker than the individual phases making up

33 the undeformed rock (Figure 1). This phenomenon raises a number of questions, which

34 need to be addressed if we are to understand how ductile shear zones in the lithosphere

35 initiate and localize strain.

36 - How do these intimate mixtures of fine-grained phases form?

37 - What controls the grain size?

38 - How is the grain-size maintained during deformation, or how does it evolve?

39 - Can we define a bulk rheology for two-phase or polyphase mixtures?

40 The purpose of this paper is to address these questions based on microphysical

41 considerations and observational data.

\section{2. Previous work}

43 The rheological properties of polyphase materials have attracted a lot of interest from

44 observational, experimental, and theoretical standpoints over several decades. It is

45 generally agreed that strain-localization in these materials results from grain-size

46 reduction, produced by some combination of metamorphic reactions, fracture and 
47 dynamic recrystallization, leading to a switch to grain-size sensitive creep (e.g., Stünitz

48 and Fitz Gerald, 1993; Fliervoet et al., 1997; Kruse and Stünitz, 1999; Kenkmann and

49 Dresen, 2002; Toy et al., 2010; Kilian et al., 2011; Linckens et al., 2011). Behrmann \&

50 Mainprice (1987), for example, documented observational evidence for simultaneous

51 crystal plastic deformation in quartz, and superplastic deformation, which involves

52 unrestricted grain-boundary sliding accommodated by some combination of diffusional

53 and dislocation creep, in fine-grained quartz-feldspar aggregates. Diffusion creep in fine-

54 grained two-phase mixtures has also been demonstrated in a number of experimental

55 studies (e.g., Bruhn et al., 1999; McDonnell et al., 2000; Ji et al., 2001; Xiao, 2002; Farla

56 et al., 2013; Tasaka et al., 2013).

57 Handy (1994), in a general review of the rheology of two-phase aggregates, made the

58 case that the rheology depends on whether the aggregate contains a load-bearing

59 framework of the stronger phase (LBF microstructure), or layers of interconnected weak

60 phase (IWP microstructure). This suggestion was supported by an experimental

61 investigation into the mechanical properties of aplite (one third quartz, two thirds

62 feldspar) by Dell'Angelo and Tullis (1996), who showed that the material initially has a

63 strength comparable to pure feldspar, but progressively weakens with strain due

64 interconnection of deformed quartz aggregates (see also Holyoke and Tullis, 2006).

65 Similarly, Bons and Urai (1994), working with camphor-octochloropropane mixtures,

66 showed that $\sim 45 \%$ of the weak phase is needed for connectivity at the start of

67 deformation, but only 25\% after 50\% shortening. Bloomfield and Covey-Crump (1993),

68 on the other hand, found that strain is partitioned nearly equally between the phases in

69 deformed calcite-halite mixtures. 
70 Considerable theoretical attention has been paid to the distribution of stress and

71 strain-rate within a deforming two-phase material. This can range between the Reuss

72 model, in which the deviatoric stress is assumed to be constant throughout the aggregate

73 and the strain-rate varies according to the mechanical properties of the different phases;

74 and the Voigt model, in which the strain-rate is assumed to be constant and the stress

75 varies between the phases. Numerous intermediate models based on various theoretical

76 considerations have also been proposed (e.g., Hill, 1965; Yoon and Chen, 1990; Tullis et

77 al., 1991; Handy, 1994; Ji and Zhao, 1994; Takeda, 1998; Ji et al., 2003; Montési, 2007);

78 useful reviews and assessments of these models are provided by Ji et al. (2001); Dimanov

79 and Dresen (2005), and Takeda and Griera (2006). Numerical modeling by Takeda and

80 Griera (2006), for example, predicts that weak-phase supported materials approximate to

81 the Voigt model, whereas strong-phase supported materials show behavior intermediate

82 between the Reuss and Voigt models. This suggests that the mechanical properties are

83 likely to evolve with strain, as the weak phase deforms and creates an IWP

84 microstructure. None of these models allow for changes in rheology resulting from

85 decreases in grain size during deformation, however, which may result in the strength of

86 the two phase composite being less than that of either of the two phases taken

87 individually (e.g., Stünitz and Fitz Gerald, 1993; Fliervoet et al., 1997; Bruhn et al., 1999;

88 Farla et al., 2013).

89 In a very detailed experimental investigation of synthetic anorthite-diopside materials,

90 Dimanov and Dresen (2005) compared their results with a range of models, and they also

91 concluded that the rheology is likely to evolve with deformation. For materials in which

92 both phases deform by dislocation creep, their data broadly support the volume averaging 
93 technique of Tullis et al. (1991), who predicted a composite flow law with parameters

94 that are volume averages of those for the two phases. This method gives results that

95 appear fit the data over the full range of volume fractions. For systems that can be

96 approximated by rigid particles in a weak matrix, the model of Yoon and Chen (1990)

97 works well for volume fractions of the strong phase in the range $0-70 \%$. The self-

98 consistent model of Hill (1965) is useful for mixtures of two linear viscous phases,

99 although it overpredicts the strength for volume fractions around 50\% (Dimanov and

100 Dresen, 2005). Most of the other models give very poor fits to the experimental data.

101 Much attention has also been paid to the question of grain-size evolution in polyphase

102 systems. This arises from the perceptions firstly, that surface-energy-driven grain growth

103 is likely to counteract grain-size reduction in deforming rocks, and hence limit the

104 potential weakening effect associated with a switch to grain-size sensitive creep (e.g., De

105 Bresser et al., 2001), and secondly that interspersed phases are likely to inhibit grain

106 growth. Much of the discussion has been couched in terms of the concept of Zener

107 pinning, in which a dispersed rigid particles of a secondary phase inhibit surface-energy-

108 driven grain-boundary migration in the primary phase (e.g., Olgaard, 1990; Evans et al.,

109 2001; Herwegh and Berger, 2004; Herwegh et al., 2005; Herwegh et al., 2011; Bercovici

110 and Ricard, 2012). In aggregates such as quartz + feldspar, olivine + orthopyroxene, or

111 calcite + dolomite, however, the grain-boundary diffusivities of the two phases are fairly

112 similar, and it may be better to describe the grain-size evolution in terms of Ostwald

113 ripening (e.g., Voorhees, 1992), or by surface-energy-driven grain-boundary migration in

114 both phases controlled by their relative diffusivities (Evans et al., 2001; Hiraga et al.,

115 2010). 
116 Another important issue that has received some attention is the role of chemical

117 reactions during the deformation of polyphase mixtures (e.g., Toy et al., 2010). Setting

118 aside the possibility of net transfer or exchange reactions related to changes in extensive

119 variables $(P, T$, water fugacity), differential diffusion of different chemical components

120 may result in phase changes at the local scale. Behrmann and Mainprice (1987), for

121 example, document the formation of tails of K-feldspar around plagioclase

122 porphyroclasts in high-T mylonites from the San Gabriel Mtns in California: this is likely

123 to result from exchange of $\mathrm{Na}^{+}$and $\mathrm{K}^{+}$between the two feldspars. Differential diffusion

124 of $\mathrm{Si}$ and $\mathrm{Mg}$ in deformed peridotites may result in migration of olivine and

125 orthopyroxene boundaries from one phase into the other (Sundberg and Cooper, 2008;

126 Hiraga et al., 2010).

\section{3. Grain-size evolution: basic principles}

128 Materials deforming by the motion of lattice dislocations tend to undergo dynamic

129 recrystallization by a variety of mechanisms (e.g., Hirth and Tullis, 1992), which

130 commonly leads to grain-size reduction. For a wide variety of both minerals and metals

131 empirical relationships have been determined showing a relationship between the mean

132 size of the dynamically recrystallized grains $d_{r}$ and the differential stress $\sigma$ of the form:

$$
d_{r}=K_{r} \sigma^{p}
$$

134 (e.g., Twiss, 1977). $K_{r}$ is a material constant, and experimental evidence suggests little or

135 no dependence on temperature or other environmental variables (e.g., van der Wal et al.,

136 1993; Stipp and Tullis, 2003; Stipp et al., 2006). The exponent $p$ varies according to the

137 material, but has values of around -1. I refer here to $d_{r}$ as the piezometric grain size. The

138 empirical relationship between $d_{r}$ and stress in several minerals has been calibrated 
139 experimentally, but only over a limited range of conditions, and the theoretical basis for

140 the relationship is still uncertain, although it is likely to be related to the relationship

141 between subgrain size and stress (e.g., Platt and Behr, 2011a).

142 Under static conditions the grain size in crystalline materials tends to increase. Two

143 processes contribute to this, both of them driven by the tendency of the system to

144 minimize surface energy. One process is the migration of grain boundaries in a single

145 phase, driven by surface energy (e.g., Evans et al., 2001). This process, referred to as

$146 \gamma$ GBM by Platt and Behr (2011a), results in the straightening of grain boundaries, the

147 development of equilibrium interfacial angles where three or more crystals meet, and the

148 shrinkage of small grains and growth of large grains leading to an overall increase in the

149 average grain size. Grain-boundary migration requires diffusion across the boundary

150 zone, a distance commonly of the order of a few nanometers. Migration may be inhibited

151 by the concentration of impurity ions near grain-boundaries (Skemer and Karato, 2007),

152 or by the presence of secondary phases along them. The second process is Ostwald

153 ripening, involving diffusion between isolated grains of a secondary phase such that

154 small grains shrink and large grains grow (Voorhees, 1992). Diffusion distances are much

155 larger, and Ostwald ripening is therefore likely to be much slower than $\gamma \mathrm{GBM}$.

156 The evolution of grain size due to $\gamma \mathrm{GBM}$ is commonly described in terms of a grain-

157 growth law of the form:

$158 d^{-n}-d_{0}^{-n}=K_{g} t$

159 (Evans et al., 2001), where $d$ is grain size, $d_{0}$ is the grain size at time $t_{0}$, and $K_{g}$ includes

160 temperature dependence following an Arrhenius function. The exponent $n$ is generally 
161 thought to be around 2 on theoretical grounds (Humphreys and Hatherly, 2004), but 162 experimental data suggest values between 2 and 5.

163 In a polyphase system $\gamma \mathrm{GBM}$ in the dominant (matrix-forming) phase is likely to be

164 inhibited by the presence of secondary phases along grain boundaries, a process known as

165 Zener pinning. In general, Zener pinning is thought to lead to a limiting grain size of the

166 matrix phase following an expression with a form such as:

$167 d_{m}=K_{z} d_{p} / f_{p}$,

168 (Evans et al., 2001) where $d_{m}$ is the limiting grain size in the matrix, $K_{z}$ includes an

169 Arrhenius type temperature dependence, $d_{p}$ is the grain size of the pinning particles, and

$170 f_{p}$ is the volume fraction of the pinning phase. The ratio $d_{p} / f_{p}$ is known as the Zener

171 parameter. The efficacy of Zener pinning is complicated by whether or not the secondary

172 phases move with the grain-boundaries or become included within the matrix grains, and

173 by the degree to which the secondary phases grow by amalgamation or by Ostwald

174 ripening. This has led to various modifications of the Zener equation, involving raising

175 either the volume fraction or the Zener parameter to some empirically determined power

176 (e.g., Herwegh et al., 2011). The uncertainties in the Zener equation and the parameter

177 values limit its value as a predictive tool.

178 There is a widespread perception that the grain size in a deforming material is

179 controlled by an equilibrium between grain-size reduction by dynamic recrystallization

180 and grain growth (e.g., Derby, 1992; De Bresser et al., 1998). There are solid grounds to

181 suggest that this is not true for the small grain sizes characteristic of many mylonites

182 (e.g., $<80$ microns for quartz, and <100 microns for olivine). At the stresses

183 corresponding to these grain sizes, grain-boundary migration is driven by the strain 
184 energy associated with lattice dislocations ( $\rho \mathrm{GBM})$, rather than by surface energy. The

185 two driving forces ( $\rho$ GBM and $\gamma \mathrm{GBM})$ produce incompatible grain-boundary

186 topologies, and act in opposite directions on curved grain-boundaries: during $\gamma \mathrm{GBM}$ the

187 grain-boundaries migrate in the direction of their concavity, whereas during $\rho$ GBM they

188 migrate in the direction of convexity (Platt and Behr, 2011a). Whichever driving force is

189 greater will therefore dominate the average microstructural evolution of the aggregate.

190 This relationship predicts a boundary in stress - grain-size space for which the driving

191 forces will be equal and opposite, referred to by Platt and Behr (2011a) as the $D_{\min }$ line,

192 given by:

$193 \quad D_{\min } \frac{C_{1}}{2}$.

$194 C_{1}$ is a material constant, and is independent of temperature; $\mu$ is the elastic modulus; and $195 \gamma$ is the interfacial energy.

196 At stresses above the $D_{\min }$ line, $\rho$ GBM will be dominant; $\gamma$ GBM will only affect the

197 smallest grains in the aggregate, or it may not take place at all. $\rho \mathrm{GBM}$ is unlikely to

198 cause grain growth in a recrystallized aggregate: the direction of grain-boundary

199 migration is largely independent of grain size, and different boundaries of the same grain

200 may migrate inwards or outwards with respect to the grain centre. Estimated locations of

201 the $D_{\min }$ lines for quartz and olivine are shown on stress-grain-size maps presented later

202 in this paper.

203 These essentially theoretical considerations are supported by observation: in

204 materials that have undergone dynamic recrystallization by either grain-boundary bulging

205 (BLG) or subgrain rotation (SGR), the average grain size of the recrystallized aggregate 
206 is usually close to or identical to the newly formed grains (e.g., Platt and Behr, 2011a).

207 Evidence for grain-growth is restricted to materials that have experienced some degree of

208 post-deformational annealing. At high temperatures this relationship breaks down; rapid

209 and irregular grain-boundary migration produces the microstructure described by Hirth

210 and Tullis (1992) as Regime 3, and by Stipp et al. (2002b, a) as GBM. This may reflect

211 deformation at stress/grain-size ratios below or along the $D_{\min }$ line.

212 There has been widespread discussion of the possibility that dynamic recrystallization

213 may result in a sufficient reduction of grain size that the dominant deformation

214 mechanism switches to some form of grain-size sensitive creep (GSSC). Possible GSSC

215 mechanisms include classical diffusion creep (Coble or Nabarro-Herring creep), pressure

216 solution creep, dislocation- or diffusion-assisted grain-boundary sliding (e.g., Langdon,

217 2006; Warren and Hirth, 2006; Hansen et al., 2011; Tasaka et al., 2014), or dislocation

218 creep in which the dominant recovery mechanism is $\rho \mathrm{GBM}$, which gives the flow law a

219 dependence on $d_{r}$ (DRX creep, Platt and Behr, 2011a). The concept of a deformation

220 mechanism switch is supported by the fact that the piezometric line for olivine, for

221 example, falls in a grain-size sensitive creep field over a significant part of the calibrated

222 range. There is no reason why this should not happen: the switch in mechanism only

223 occurs once a fine-grained dynamically recrystallized aggregate has formed, and the

224 recrystallization process affects grains that may themselves be much larger, and hence lie

225 in the dislocation creep field. On the other hand, De Bresser et al. (1998) and De Bresser

226 et al. (2001), among many others, have suggested that once the switch occurs, grain-size

227 reduction processes will cease, and grain growth will take over, possibly reversing the

228 switch in mechanism. This question needs to be examined carefully. The argument 
229 advanced by De Bresser et al. (2001) was based on the assumption that a switch in

230 deformation mechanism would result in a stress drop. This might cause the material to

231 drop below the $D_{\text {min }}$ line in stress - grain-size space, in which case $\gamma$ GBM could drive

232 grain growth. In a natural shear zone, the effect of a switch in deformation mechanism is

233 more likely to cause an increase in strain-rate, and depending on the external boundary

234 conditions, the stress may not drop at all (Platt and Behr, 2011b). In this case, dislocation

235 activity and dynamic recrystallization will continue at approximately the same level - the

236 switch in mechanism is a result of an increase in the rate of GSSC, rather than a decrease

237 in the rate of dislocation creep. Several GSSC mechanisms depend on dislocation

238 activity in any case (e.g., disGBS and DRX creep).

239 In a deforming polycrystalline aggregate the situation is more complicated. Many

240 studies have shown that the grain size in the multi-phase aggregates is substantially less

241 than the dynamically recrystallized grain size for at least one of the phases where it

242 occurs in single-phase layers (e.g., Behrmann and Mainprice, 1987; Stünitz and Fitz

243 Gerald, 1993; Kruse and Stünitz, 1999; Kenkmann and Dresen, 2002; Kilian et al., 2011;

244 Linckens et al., 2011). The aggregate may therefore be subject to a driving force for

245 grain growth. Growth will be slowed or limited, however, by phase mixing, and also by

246 grain-boundary sliding. Inhibition of grain growth by phase mixing has been widely cited

247 as the reason fine-grained ultramylonites persist (Olgaard, 1990; Stünitz and Fitz Gerald,

248 1993; Krabbendam et al., 2003; Herwegh and Berger, 2004; Farla et al., 2013), and for

249 this reason in the analysis below I neglect the effects of grain growth (I discuss the limits

250 of this assumption and a possible test below). The question remains, however, how the

251 fine-grained mixtures form in the first place. 


\section{4. Formation of fine-grained two-phase mixtures}

253 The critical question raised by polyphase ultramylonites is the process by which fine-

254 grained intimate mixtures of two or more phases can form. A variety of mechanisms can

255 be envisaged, including crystallization of phases from initially fine-grained or glassy

256 material, such as volcanic rocks or pseudotachylite; exsolution of a second phase

257 (Linckens et al., 2011) or the crystallization of new phases during retrogressive

258 metamorphism (White and Knipe, 1978; Brodie and Rutter, 1987); and the formation of

259 symplectites around initially coarse-grained phases. The grain size produced by these

260 processes is not readily predictable, and may subsequently evolve as the result of either

261 dynamic recrystallization or surface-energy-driven grain growth.

262 A common process in initially coarse-grained two-phase systems that does not

263 necessarily involve phase changes is the formation of dynamically recrystallized tails

264 around porphyroclasts. A number of workers have suggested that the nucleation of new

265 phases within porphyroclast tails can produce mixed-phase aggregates (e.g., Kruse and

266 Stünitz, 1999; Kenkmann and Dresen, 2002). An example is illustrated in Figure 2, which

267 shows a tail of dynamically recrystallized material forming around a large porphyroclast

268 of sodic plagioclase in a mylonitic granitoid from the Aspromonte massif in southern

269 Italy (Platt and Compagnoni, 1990). The tail contains a significant amount of dispersed

270 quartz (Fig. 2a), and the resulting quartz-feldspar mixture is significantly finer-grained

271 than in the ribbons of dynamically recrystallized quartz that formed from originally

272 coarse-grained quartz in the protolith (Fig. 2b). It is common in mylonitic granitoids to

273 find quartz infilling fractures in feldspar porphyroclasts: the relatively coarse grain size of

274 the infilling quartz, and the lack of indications of crystal-plastic deformation, suggest that 
275 it was emplaced by a solution-reprecipitation mechanism. An example of this is

276 illustrated in Figure 3: quartz infills cracks at the margin of a K-feldspar porphyroclast in

277 a mylonite from the Whipple Mtns metamorphic core complex, and the quartz is mixed

278 with recrystallized feldspar in the tail (Figure 4a). EBSD images of the quartz-feldspar

279 mixture in the tail show the intimate mixing of the two phases (Figs $4 \mathrm{~b}, \mathrm{c}$ ). The effect of

280 this mixing on the grain size and CPO are shown by an ultramylonitic granitoid from the

281 Aspromonte massif in Calabria (Figures 5 and 6). Tails around plagioclase porphyroclasts

282 (Figure 5) show fine-grained mixtures of quartz and dynamically recrystallized

283 plagioclase; the relatively coarse grained quartz in adjacent quartz ribbons has a grain

284 size of $\sim 40-50 \mu \mathrm{m}$ and a strong CPO, whereas both quartz and feldspar in the mixed tails

285 have a grain size of 13-15 $\mu \mathrm{m}$ and weak and disorganized CPO (Figure 6).

286 In neither of the two examples discussed above is there any evidence of metamorphic

287 reactions contributing to the process. The feldspars have deformed by a combination of

288 brittle fracture and intracrystalline plasticity, leading to dynamic recrystallization,

289 without any change in composition, and without breaking down to other phases. The

290 admixture of quartz in the recrystallized tails appears to be the result of diffusion

291 (probably by dissolution-precipitation) of silica from outside the porphyroclast system.

292 These observations suggest a relatively simple mechanism for the formation of fine-

293 grained mixtures by deformation of initially coarse-grained two-phase aggregates, as set

294 out in the following generic scenario (Figure 7).

295 1. Dislocation creep and dynamic recrystallization of both phases reduces the overall

296 grain size. The stronger phase will tend to form porphyroclasts, and if it has a

297 dynamically recrystallized grain size smaller than that of the matrix phase, the grain 
size in the recrystallized tails will be less than that in the surrounding matrix. This relationship is common observed in quartz-feldspar and olivine-orthopyroxene rocks. Brittle fracture processes and metamorphic reactions may also play a role in grain size reduction, and in feldspars it can be difficult to distinguish grain refinement by frictional slip on cleavage planes from dynamic recrystallization (Dell'Angelo and Tullis, 1996).

304 2. If the grain size is sufficiently reduced by dynamic recrystallization, one or both

305 phases may deform more rapidly by grain-boundary diffusion creep rather than

306 dislocation creep (by grain-boundary diffusion creep I refer here both to classical

307 Coble creep and to pressure solution creep).

308 3. Grain-boundary diffusion creep requires grain-boundary sliding, and tends to open up

309 potential voids between the grains, which are filled by diffusion. This allows

310 diffusion of the matrix phase into the dynamically recrystallized tails around the

311 porphyroclasts. Note that this process implies the nucleation and growth of grains of

312 the diffusing phase. This process was documented by Behrmann and Mainprice

313 (1987), where K-feldspar fills pull-aparts in fine-grained plagioclase aggregates. The

314 size of the new grains of the diffusing phase is controlled by the spaces that form

315 between grains of the phase making up the tail, and hence can lead to even mixing

316 and dispersion of the two phases, with a grain size controlled by that of the

317 porphyroclastic phase.

318 4. The rheology of the resulting aggregate will therefore be controlled by a combination

319 of grain-boundary diffusion creep and grain-boundary sliding, with a grain size

320 controlled by dynamic recrystallization of the porphyroclastic phase. 
321 The process suggested above is a postulate, and would be difficult to test experimentally,

322 as it requires large strains to reach steady state microstructures and grain sizes. In the next

323 section I follow the reasoning set out above to characterize the rheology of a mylonitic

324 granitoid formed by this process, and I then suggest a possible observational test.

\section{5. Flow law for a mylonitic granitoid}

326 Both quartz and feldspar in a granitoid rock at temperatures above $\sim 450^{\circ} \mathrm{C}$ will

327 deform, initially at least, by dislocation creep. If dislocation climb is the main recovery

328 mechanism, the flow law is likely to be power-law with a stress exponent in the range 3-

329 5, and will not be sensitive to grain size. Tullis et al. (1991) proposed that a two-phase

330 material in which both phases deform by dislocation creep will obey a bulk flow law in

331 which the parameters are averaged by volume as follows (subscript $a$ refers to the

332 aggregate, subscripts 1 and 2 to the two phases, and $\phi$ is volume fraction):

333 The power law exponent $n_{a}$, the activation energy $Q_{a}$, and the prefactor $A_{a}$ are the

334 given by:

$335 \log n_{a}=\phi_{1} \log n_{1}+\phi_{2} \log n_{2}$,

$336 Q_{a}=\left[Q_{2}\left(n_{a}-n_{1}\right)-Q_{2}\left(n_{a}-n_{2}\right)\right] /\left(n_{2}-n_{1}\right)$,

$337 \log A_{a}=\left[\log A_{2}\left(n_{a}-n_{1}\right)-\log A_{1}\left(n_{a}-n_{2}\right)\right] /\left(n_{2}-n_{1}\right)$.

338 As discussed above, this averaging technique corresponds reasonably well to

339 experimental data, particularly for high volume fractions of the stronger phase, which is

340 the case for granitoid rocks. It tends to overestimate the strength for low volume fractions

$341(<40 \%)$ of the stronger phase (Dimanov and Dresen, 2005). It has the disadvantage that

342 it falls down if the power law exponents for the two phases are too close. For the systems

343 discussed here, however, the two minerals show significantly different exponents. Flow 
344 law parameters used in this paper for dislocation creep in quartz and feldspar are given in

345 Table 1.

346 Experimental evidence suggests that solid-state grain-boundary diffusion creep

347 (Coble creep) is very unlikely in quartz under geological conditions, even at fine grain

348 sizes (Rutter and Brodie, 2004). An important alternative process of diffusion creep in a

349 granitic mylonite at low or moderate temperatures is likely to be water-assisted diffusion

350 of silica along grain-boundaries and fractures (den Brok, 1998; Farver and Yund, 2000).

351 This process, commonly known as pressure-solution creep, has been described in terms

352 of a number of flow laws, depending on the nature of the diffusion pathway, the source-

353 to-sink distance of diffusion, and the presence or absence of advection (e.g., den Brok,

354 1998; Gratier et al., 1999). Strain-rate-grain size, stress-strain-rate, and stress-T plots for

355 the three main flow laws (island-channel, stress corrosion, and thin-film) proposed for

356 pressure solution are shown in Figure 8 (methods of calculation are given in the

357 Appendix), together with the dislocation creep flow law of Hirth et al. (2001). In general,

358 at temperatures and stresses characteristic of ductile deformation, strain-rates in quartz

359 predicted by the island-channel and stress-corrosion models are $\sim 5$ orders or more of

360 magnitude faster than dislocation creep, which rules them out as viable processes in a

361 rock that has clearly deformed largely by crystal plasticity. Under these same conditions,

362 grain-boundaries are likely to be tight, and advection limited, in which case the thin-film

363 model for pressure solution is most likely to be applicable. The flow law for the thin-film

364 model has a form analogous to that for Coble creep:

$365 \quad \dot{e}=\frac{C_{2} V_{f} c D w}{{ }_{s} R T d^{3}}$, 
366 where $C_{2}$ is a shape constant (taken to be 44 for spherical grains), $V$ is molar volume, $\rho_{f}$

367 and $\rho_{s}$ are the densities of fluid and solid phases; $c$ is the solubility of the solid in the fluid

368 phase as a mole fraction; $D$ is the diffusivity of the solid in the grain-boundary fluid film;

$369 w$ is the grain-boundary width, sigma is differential stress, $R$ is the gas constant, $T$ is

370 temperature, and $d$ is the grain size or source to sink distance (parameter values are given

371 in the Appendix). Note that the strain-rate has a linear relationship to stress and a grain-

372 size sensitivity exponent of 3 . The grain size of the quartz is assumed to be the same as

373 the feldspar, and hence governed by the piezometric relationship for sodic plagioclase

374 (Post and Tullis, 1999), as discussed in the previous section. It is likely that the

375 piezometric relationship varies with the composition of the plagioclase, and is different

376 for K-feldspar, but experimental data are not available.

377 The experimental data of Rybacki et al. (2006) for wet fine-grained anorthite suggests

378 that rates of diffusion creep in feldspar may be comparable to those produced by

379 pressure-solution creep in quartz under the conditions discussed here (Figure 9). Granites

380 contain sodic plagioclase and K-feldspar, rather than anorthite, but the detailed

381 observational evidence provided by Stünitz and Fitz Gerald (1993) and Kilian et al.

382 (2011) suggests that the rates of granular flow in quartz, albite, and K-feldspar are all

383 very similar in fine-grained mixtures of these minerals. This suggests that a quartz-

384 feldspar aggregate can be treated as a mixture of two linear viscous phases. I have

385 therefore used the experimental data for diffusion creep of anorthite together with the

386 flow-law for thin-film pressure solution creep in quartz, and applied the self-consistent

387 mixing law:

$3883 \mu_{a}^{2}+\left[2\left(\mu_{1}+\mu_{2}\right)-5\left(\phi_{1} \mu_{1}+\phi_{2} \mu_{2}\right)\right] \mu_{\mathrm{a}}-2 \mu_{1} \mu_{2}=0$, 
389 where $\mu_{a}$ is the bulk viscosity of the aggregate, and $\mu_{1}$ and $\mu_{2}$ are the viscosities of the

390 two phases (see discussion by Dimanov and Dresen, 2005). This mixing law may

391 overpredict the strength for volume fractions around 50\% (Dimanov and Dresen, 2005),

392 but this is unlikely to be important if the viscosities of the two phases are similar.

393 We therefore use two different mixing laws to determine composite flow laws for

394 dislocation creep and diffusion creep. These two mechanisms are independent, so it is

395 reasonable to assume that the total aggregate strain-rate is the sum of the strain-rates

396 produced by the two mechanisms (Montési and Hirth, 2003). For the purposes of this

397 discussion I have not allowed for any additional component of strain-rate accommodated

398 by grain-boundary sliding (GBS). GBS is in any event an essential component of grain-

399 boundary diffusion creep (Langdon, 2006), and is not normally treated separately in flow

400 laws for this mechanism. Unrestricted grain-boundary sliding, which is thought to be

401 responsible to superplastic behavior, may contribute substantially to the strain-rate. The

402 approach taken here is therefore conservative, in that it does not take this contribution to

403 the strain-rate into account. Eqns 5 , 6, and 7 lead to a bulk flow law as follows:

$404 \quad \dot{e}=A_{a}{ }^{n_{a}} \exp \frac{Q_{a}}{R T} \div+\frac{}{2_{a}}$.

405 The bulk viscosity $\mu_{a}$ is calculated from Eqn 8 using viscosity terms for thin-film

406 pressure solution creep in quartz and for diffusion creep in feldspar given by:

$$
{ }_{q p s}=\frac{{ }_{s} R T d^{3}}{2 C_{2} V_{f} c D w} \text { and }{ }_{\text {diff }}=\frac{d^{3}}{2 A f\left(H_{2} O\right) \exp (Q / R T)} .
$$

409 Parameter values for these equations are listed in the Appendix (for pressure solution 410 creep) and in Table 1, and the volume fraction of feldspar is taken to be 0.4. As discussed 
411 above, the mixing laws I have used appear be approximately valid over the whole range

412 of volume fractions.

413 A stress-grain-size deformation mechanism map for a granitoid rock obeying this

414 composite flow law is shown in Figure 9a. In the right hand field labelled "dislocation

415 creep", the grain size is large enough that the second term in Eqn 7 is negligible, and the

416 rock deforms by dislocation creep in both quartz and feldspar. In the left-hand field

417 labelled "diffusion creep", an ultramylonite formed by phase mixing as described in

418 Section 4 deforms by thin-film diffusion creep in quartz, and by diffusion creep in

419 feldspar, and the second term in Eqn 7 contributes the bulk of the strain rate. The map

420 does not correctly predict the behavior of the material during the process of grain size

421 reduction, when it may show a very large range of grain sizes, and the two styles of

422 deformation co-exist in different parts of the rock. It does, however, provide a useful

423 guide to the change in material properties consequent upon the conversion of the rock

424 from a coarse-grained granitoid (point A in Figure 9c), to an ultramylonite (point B),

425 assuming constant stress during deformation. In this case, there is $>4$ orders of

426 magnitude increase in strain rate resulting from the change. A map for quartz under the

427 same conditions is shown for comparison (Figure 9a) - in the dislocation creep field pure

428 quartzite deforms several thousand times faster than granite, but under the conditions of

429 point $\mathrm{B}$, the two materials deform at similar rates.

430 These maps and the conclusions drawn from them are only as good as the flow laws

431 and the piezometers on which they are based, and will need revision as more

432 experimental data for quartz and feldspar become available. Also, the flow law for a

433 granitoid ultramylonite derived here only applies to that part of the rock that consists of a 
434 fine-grained two-phase mixture, formed by the mechanism proposed in this paper. Real

435 mylonitic rocks, including the ones discussed and illustrated here, are commonly

436 composed of layers with different compositions, formed by deformation and dynamic

437 recrystallization from different protolith minerals. The bulk rheology of such composite

438 materials depends on the relative volume proportions of the different layers, and their

439 degree of connectivity. The rheology of the two-phase mixture is an essential component

440 of the bulk rheology, and may dominate it, but it is not the whole story.

441 Another issue is the role of pressure solution in the process discussed here. Pressure

442 solution is a very poorly understood process, and there is little reliable experimental data

443 to constrain the flow laws. Three different flow laws have been proposed, based on

444 different descriptions of the diffusion pathway, which predict strain rates differing by

445 many orders of magnitude. It is possible that these different pathways are influenced or

446 activated by temperature, deviatoric stress, and fluid pressure; at present we have no

447 constraints on this. Pressure solution is critically dependent on the presence of water,

448 either as a fluid phase or a grain-boundary film. Changes in fluid pressure driven by

449 hydration or dehydration reactions may dramatically affect the rate of pressure solution

450 creep. Partial melting, which in granitoid rocks may start at around $650^{\circ} \mathrm{C}$, will severely

451 lower water activity, as water partitions into the melt, and this may limit the activity of

452 pressure solution creep at higher temperatures.

453 There are also limits on grain-size reduction processes in deformed rocks. At higher

454 temperatures, deviatoric stress is lower, and the material may pass into the stress-grain-

455 size field where surface-energy driven grain-boundary migration becomes dominant. The

456 grain size will no longer be controlled by the piezometric relationship, and the switch to 
457 grain-size sensitive creep may no longer occur. This point may correspond to the

458 intersection of the $D_{\min }$ line (see above) with the piezometer - an estimated position for

459 this in quartz ( 60 $\mu \mathrm{m}$ grain size and $18 \mathrm{MPa}$ shear stress) is shown in Figure 9a. In the

460 crust, this is likely to occur at a temperature of $\sim 450^{\circ} \mathrm{C}$ (Behr and Platt, 2011). The

461 position of the $D_{\min }$ line for feldspar, unfortunately, is not known.

462 A possible test for the operation of the mechanism described here is to determine the

463 flow stress from the dynamically recrystallized grain size of pure quartz bands or

464 aggregates, and then see if the grain size of quartz feldspar mixtures in the same rock

465 corresponds to that predicted by the feldspar piezometer. I have done this for a number

466 of published descriptions of ultramylonitic granitoids, as well as the two examples

467 described in this paper (Table 2). The results, though few in number, seem consistent 468 with the hypothesis.

\section{6. Olivine-orthopyroxene mixtures}

470 The olivine-orthopyroxene system differs from the quartz-feldspar system in several 471 ways. The two minerals share many deformational characteristics, and the contrast in

472 dislocation creep strength between them is likely to be much less than between quartz and

473 feldspar; the presence of an aqueous phase is unlikely under most conditions, though a

474 melt phase may be present; and the similarity in composition of the two minerals may

475 allow grain-boundary migration and grain-boundary diffusion creep in a mixed aggregate

476 to proceed by the diffusion of a single component (e.g., MgO). Recent observational and

477 experimental work on the behavior of the system requires some review. 
487 of grain-size sensitive creep in the fine-grained mixture.

493 confining pressure in a solid-medium apparatus, in the orthoenstatite stability field. In

494 both sets of experiments a low stress exponent of the mixture suggested a component of 495 diffusion creep, accompanied by grain-boundary sliding.

496 Tasaka and Hiraga (2013) carried out a very detailed experimental analysis of 497 syndeformational grain-growth kinematics in extremely fine-grained forsterite-enstatite 498 mixtures in a gas-medium apparatus, and discussed the results in terms of a Zener

499 pinning model. This group also presented results from a long set of rheological 500 experiments on similar materials (Tasaka et al., 2013), carried out at constant 
501 displacement rate. Samples with very low enstatite contents show power law creep with

502 stress exponent of 3 and no grain-size sensitivity, but at higher enstatite contents the

503 stress exponent drops to around one and the grain-size sensitivity is 2 . They interpret this

504 as indicating grain-boundary sliding, with a change in the accommodation mechanism

505 from dislocation creep to diffusion creep with increasing enstatite content. All their

506 experiments were carried out at low pressures, and hence outside the stability field of

507 orthoenstatite.

508 Farla et al. (2013) also carried out experiments on fine-grained olivine-orthopyroxene

509 mixtures, using a solid-medium direct-shear apparatus at high pressure, so that the

510 experiments lay in the orthoenstatite stability field. Their experiments suggest that the

511 mixtures are significantly finer-grained and weaker than pure olivine deformed under the

512 same conditions, due to a switch to grain-size sensitive creep. They attribute the mixing

513 of the two-phases to neighbour-switching during grain-boundary sliding.

514 Linckens et al. (2014) carried out experiments on initially coarse-grained olivine-

515 orthopyroxene mixtures, also using a solid-medium apparatus. They noted that the

516 dynamically recrystallized orthopyroxene is 5-10 times finer grained than the olivine, and

517 calibrated an orthopyroxene piezometer using the grain size of the olivine and the

518 experimental piezometer for olivine of van der Wal et al. (1993). They saw very minor

519 mixing of the two phases during the experiments, and concluded that the processes

520 leading to a well-mixed microstructure are inefficient at the conditions achieved in their

521 experiments. 
522 Bruijn and Skemer (2014) use the results of experiments reported in an unpublished

523 thesis (Lawlis, J.D., 1998, High temperature creep of synthetic olivine-enstatite

524 aggregates, $\mathrm{PhD}$ thesis, Dept. of Geosciences, Pennsylvania State University,

525 State College, PA.) to construct flow laws for orthopyroxene. The dislocation creep flow

526 law is based directly on experiments designed to determine the flow-law parameters; they

527 then use deviations from this law at fine grain sizes to determine two data points for a

528 diffusion creep flow law, based on assumptions about the factors controlling the grain

529 size. The experiments were carried out in a solid medium apparatus in the stability field

530 of orthopyroxene, and hence are probably the most reliable results available, so I use the

531 dislocation creep flow law in the following discussion (Table 1). For the diffusion creep

532 flow law (Table 1), I chose values of the parameters given by Tasaka et al. (2013) within

533 the uncertainties such that the flow law fits the two data points inferred by Bruijn and

534 Skemer (2014).

\section{Summary of conclusions reached to date}

536 There is a general consensus that phase mixing in olivine-pyroxene aggregates leads to

537 substantial weakening, and that this is likely to be a result of a switch to GSSC, probably

538 involving an important component of grain-boundary sliding. The mechanism of mixing

539 remains uncertain, and has been attributed to solution-redeposition involving an

540 unspecified fluid phase, grain-boundary diffusion, or grain-boundary sliding with

541 neighbour-switching. Controls on the grain size of the mixture remain uncertain, with

542 most theoretical discussion focusing on grain growth governed by Zener pinning, rather

543 than the processes of grain-size reduction that produce the fine-grained mixture. Flow 
544 laws for the fine-grained mixtures remain debated: stress exponents in the range 1-2, and

545 grain-size exponents in the range 2 to 3 , have been suggested or assumed.

546 A postulate for the behavior and flow laws of olivine-orthopyroxene mixtures

547 Microstructural evidence suggests that the processes and effects involved in the

548 formation of fine-grained olivine-orthopyroxene mixtures may be analogous to those

549 suggested above for quartz-feldspar mixtures. This is illustrated in Figure 10, which

550 shows an orthopyroxene porphyroclast system in a xenolith from the Jagersfontein

551 kimberlite in South Africa. These xenoliths were studied in some detail by Skemer and

552 Karato (2008), and Figure 10 is redrawn from an EBSD map of the porphyroclast and its

553 tail published by Bruijn and Skemer (2014). The map shows dynamic recrystallization on

554 the margin of the porphyroclast, probably largely by the SGR mechanism, with some

555 contribution from $\rho$ GBM. Grain size in the orthopyroxene is reduced by dynamic

556 recrystallization from several $\mathrm{mm}$ to $\sim 50 \mu \mathrm{m}$, and further grain size reduction takes place

557 in the tail with distance away from the porphyroclast. These values suggest a differential

558 stress of 15-20 MPa, according to the paleopiezometer constructed by Bruijn and Skemer

559 (2014). The dramatic increase in strain of the orthopyroxene in the tail relative to the

560 porphyroclast suggests a switch to grain-size sensitive creep. The interesting aspect of the

561 recrystallized tail from the perspective of this paper is the presence of small grains of

562 olivine mixed in with the orthopyroxene. These grains are completely isolated within the

563 orthopyroxene tail, but tend to decrease in abundance with distance away from the

564 coarse-grained olivine on either side of the tail (Figure 10). This suggests a diffusional

565 mechanism for mixing. Given the widespread development of olivine-orthopyroxene 
566 mixtures in high-strain peridotites, I suggest that diffusional mixing, with grain size

567 controlled by dynamic recrystallization in the orthopyroxene, is a common mechanism.

568 To assist the discussion, deformation mechanism maps for pure olivine and pure

569 orthopyroxene are shown in Figure 11a-d, using the parameters listed in Table 1. These

570 show that in both the dislocation creep and diffusion creep fields, olivine deforms about

571 two orders of magnitude faster than orthopyroxene, with the difference in rate decreasing

572 at high temperature and low stress. The stress-temperature maps (Figures $11 \mathrm{~b}$ and d) are

573 constructed assuming that the grain size follows the piezometric laws for the two

574 minerals. These suggest that at strain-rates in the range $10^{-15}$ to $10^{-11}$, dynamic

575 recrystallization will cause olivine to switch to diffusion creep below a temperature in the

576 range $800-900^{\circ} \mathrm{C}$; whereas orthopyroxene will switch below $1000-1050^{\circ} \mathrm{C}$. Above these

577 temperature ranges the dominant deformation mechanism in each mineral is dislocation

578 creep. The reason for this behavior is illustrated in the stress-grain-size maps (Figures

579 11a and c): these show that if the grain size follows the piezometric relation, there is a

580 switch to diffusion creep at higher stresses and hence smaller grain sizes, which for any

581 given strain-rate are required at lower temperatures.

582 At any given stress, below $\sim 500 \mathrm{MPa}$, the piezometer for orthopyroxene predicts

583 significantly finer grain sizes than the piezometer for olivine. If, as I postulate above for

584 the two-phase mixture, the grain size in the olivine is controlled by the piezometric

585 relationship for orthopyroxene, then the recrystallized olivine will lie in the diffusion

586 creep field over a wide range of stress and temperature space. This therefore suggests a

587 scenario based on the following assumptions, some of which still need to be tested. 
588 1. In a coarse-grained peridotite, both olivine and orthopyroxene deform by dislocation

589 creep, and the grain size will be reduced following the respective piezometers for the

590 two minerals (Figure 11a and c).

591 2. Over a wide range of conditions, orthopyroxene will switch into the diffusion creep

592 field as a result of grain-size reduction (Figure 11c). Diffusion rates in the olivine are

593 likely to be around two orders of magnitude faster than in the orthopyroxene,

594 however, and hence olivine can diffuse into the spaces that open up around the

595 orthopyroxene grains due to grain-boundary sliding.

596 3. The grain size of the olivine where it is mixed with the orthopyroxene is

597 approximately that of the dynamically recrystallized orthopyroxene, and this governs

598 the rate of diffusion creep in the olivine.

599 4. If the shear zone is operating at constant stress, dislocation creep and dynamic

600 recrystallization will continue in both phases, even though diffusion creep is the

601 dominant deformation mechanism. This, and the mixing of the two phases, will

602 largely inhibit surface-energy driven grain growth.

603 I have not introduced any other grain-size sensitive creep mechanisms into this

604 discussion. The most widely discussed mechanism is Dis-GBS (e.g., Hansen et al., 2011),

605 but the flow-law parameters for this mechanism are uncertain, and there is limited

606 microstructural evidence for grain-boundary sliding in mylonitic peridotites. The other

607 possibility is DRX creep (Platt and Behr, 2011a), but the flow law is very sensitive to the

608 grain-boundary mobility, which for olivine is uncertain to within at least 3 orders of

609 magnitude (Evans et al., 2001). Addition of these mechanisms may change the details of

610 the processes discussed here, but are unlikely to change the overall conclusions. 
611 At temperatures below $1000-1050^{\circ} \mathrm{C}$, a peridotitic ultramylonite is likely to deform

612 predominantly by diffusion creep in both olivine and orthopyroxene. The fine-grained

613 aggregate can therefore be treated as a mixture of two linear viscous phases, and so I

614 have used the self-consistent mixing law (Eqn 9).

615 Stress-grain-size and stress-temperature deformation mechanism maps for

616 harzburgite, incorporating dislocation creep in both phases using the parameter-averaging

617 method of Tullis et al. (1991), and diffusion creep for both phases after dynamic

618 recrystallization, are shown in Figure 11 e and $\mathrm{f}$. As noted for above for a granitoid, the

619 stress-grain-size map does not correctly predict the behavior of the material during the

620 process of grain-size reduction, but it shows how the material properties of the mixture

621 will change during dynamic recrystallization to an ultramylonite. At constant stress, the

622 change would result in an increase in strain rate by a factor of $\sim 20-40$ at $900^{\circ} \mathrm{C}$. This

623 result is weakly dependent on stress, but decreases significantly with temperature: at

$624700^{\circ} \mathrm{C}$ the strain-rate increases by three orders of magnitude; above $\sim 1050^{\circ} \mathrm{C}$,

625 deformation remains in the dislocation creep field, and no weakening is predicted.

626 The shaded area in Figure 11f is a region of stress-T space in which the deformation

627 mechanism map for orthopyroxene predicts that it will be in the dislocation creep field,

628 but the olivine, if it has a grain size controlled by the piezometric relation for

629 orthopyroxene, will be deforming by diffusion creep. In that case mixing of the two

630 phases might be much slower, and the self-consistent mixing law for two linear viscous

631 phases would not apply. The predicted deformation mechanism and strain-rates in this

632 area are therefore likely to be unreliable. 


\section{Discussion and Conclusions}

634 The analysis presented here suggests that the formation of fine-grained two-phase or

635 polyphase mixtures in ultramylonites may in part result from a combination of dynamic

636 recrystallization accompanying initial crystal-plastic deformation in both phases, which

637 leads to grain-size sensitive creep accompanied by grain-boundary sliding, which in turn

638 leads to diffusion of each phase into spaces opened up by grain-boundary sliding in the

639 other phase. Flow in the resulting mixture takes place by diffusion creep of both phases,

640 while the grain size is controlled by the piezometric relationship for whichever phase

641 recrystallizes to the finer grain size. This can lead to an increase in strain rate (at constant

642 stress) relative to the initial coarse-grained material by more than four orders of

643 magnitude, particularly at low temperatures. This is likely to be of major significance in

644 promoting strain localization in the ductile field.

645 The process described here is likely to be most applicable to materials such as

646 granitoid rocks, peridotites, and calcite-dolomite rocks, in which syn-kinematic

647 metamorphic reactions and phase changes do not play a significant role. In mafic and

648 pelitic rocks, for example, ductile deformation is commonly accompanied by

649 metamorphic reactions, and the rheology is likely to be strongly modified by diffusional

650 processes accompanying those reactions, by the strength (or weakness) and anisotropy of

651 the resulting new phases, and by fluctuations in fluid pressure and water activity

652 accompanying hydration and dehydration reactions. These complexities are not addressed

653 in this paper.

654 The composite flow laws presented here are subject to the uncertainties in the

655 experimental and theoretical data for the individual phases, and they depend on the 
656 mixing laws that I have applied, which are approximate and are not universally valid. As

657 far as I can tell, for the two systems studied here, the mixing laws should be valid over

658 the full range of volume fractions. The Tullis et al. averaging technique, however, falls

659 down if the power law exponents for the two phases are too close.

660 There are several problems with the flow laws I have used. In the absence of

661 experimentally determined flow laws for sodic plagioclase and K-feldspar, I have used

662 experimental data for anorthite, and applied it to granitic rocks. The pressure solution

663 flow law I used has not been experimentally verified. I believe that the estimated strain-

664 rates are likely to be conservative, however, as several factors may result in higher

665 values. Firstly, I have neglected several contributors to grain-size sensitive creep, which

666 may result in higher strain rates. These include unlimited grain-boundary sliding with

667 neighbor swapping (superplasticity), and dislocation creep with grain-boundary migration

668 as a recovery mechanism (DRX creep). Second, I have chosen conservative values for

669 pressure solution creep. Thin-film pressure solution is the slowest of the postulated

670 pressure-solution mechanisms: much higher rates may occur if fluid pressure and content

671 are sufficient to produce fluid-filled channels. The diffusion creep flow law for olivine is

672 likely to be rate-controlled by diffusion of $\mathrm{SiO}_{2}$, which is relatively slow (Hiraga et al.,

673 2010). At least the initial stages of diffusional mixing of olivine and orthopyroxene,

674 however, may be controlled by the more rapid diffusion of $\mathrm{MgO}$, which converts

675 orthopyroxene to olivine at the sink position, and olivine to orthopyroxene at the source

676 position.

677 Another limitation to the method is the assumptions that the grain size is controlled

678 by experimentally determined piezometers, and that there is no surface-energy-driven 
679 grain growth. These assumptions are likely to break down at low stresses, equivalent to

680 dynamically recrystallized grain sizes above $\sim 60 \mu \mathrm{m}$ for quartz, and $100 \mu \mathrm{m}$ for olivine,

681 corresponding to the intersection of the piezometer with the $D_{\min }$ line for each mineral.

682 As pointed out earlier, the flow laws for two-phase ultramylonites derived here only

683 apply to the relatively narrow bands of ultramylonite that are interleaved at all scales with

684 layers with different compositions and deform by different mechanisms. Much work

685 remains to be done to determine how the bulk rheology in deforming zones is controlled

686 by this complexity in the microstructure.

\section{Acknowledgements}

688 This research was supported by the Southern California Earthquake Center (SCEC).

689 SCEC is funded by National Science Foundation Cooperative Agreement EAR-1033462

690 and USGS Cooperative Agreement G12AC20038. The SCEC contribution number for

691 this paper is 2059. I thank Whitney Behr, Rüdiger Killian, and Elena Miranda for

692 discussions and advice on sample preparation and indexing, and Georg Dresen and an

693 anonymous reviewer for their very helpful comments, which contributed substantially to

694 the improvement of the manuscript.

695

696 Appendix

697 Calculation of pressure solution flow laws

698 Pressure solution flow laws were calculated from expressions given by den Brok (1998)

699 for the thin-film, island channel, and stress-corrosion models, using the following

700 methods and parameters: 
$701 V$ : molar volume of solid $\quad 2.269 \mathrm{e}-5$ (Berman, 1988),

$702 \rho_{f}:$ density of fluid phase $\quad 0.923$,

$703 \rho_{s}$ : density of solid phase 2.65 ,

704 grain-boundary width $w=2 \mathrm{E}-9 \mathrm{~m}$ (Farver and Yund, 2000).

705 The solubility $c$ of the solid in the fluid phase was calculated using expressions from

706 Fournier and Potter (1982), using values for the specific volume of water interpolated

707 from tabulated values from Burnham et al. (1969). The grain-boundary diffusivity $D_{\mathrm{gb}}$ of

708 the solid in the grain-boundary fluid film was calculated from the bulk diffusivity,

709 following Farver and Yund (2000), as follows:

$710 D_{\mathrm{b}}=D_{0} \exp \left(-\mathrm{Q}_{\mathrm{b}} / \mathrm{RT}\right)$, and $D_{\mathrm{gb}}=D_{\mathrm{b}} * 1.2 \mathrm{e}-6 . /(\operatorname{tau} * 2 \mathrm{e}-9)$, where $D_{0}=3.7 \mathrm{E}-10$ and

$711 \mathrm{Q}_{\mathrm{b}}=137000$; and the tortuosity factor $\tau=1.75$.

712 The diffusivity of silica in water $=2.8 \mathrm{e}-5 * \exp (-6300 . / \mathrm{T})($ Watson and Wark, 1997).

713 Length scales of the diffusion paths for the different flow laws are grain size $=20 \mu \mathrm{m}$ for

714 the thin film model, the channel width for the island channel model $=0.1 \mu \mathrm{m}$, and the

715 island diameter $=0.5 \mu \mathrm{m}$ for the stress-corrosion model.

\section{References}

717 Behr, W.M., Platt, J.P., 2011. A naturally constrained stress profile through the middle

718 crust in an extensional terrane. Earth and Planetary Science Letters 303, 181-192.

719 Behrmann, J., Mainprice, D., 1987. Deformation mechanisms in a high-temperature

720 quartz-feldspar mylonite: evidence for superplastic flow in the lower continental

$721 \quad$ crust. Tectonophysics 140, 297-305. 
722 Bercovici, D., Ricard, Y., 2012. Mechanisms for the generation of plate tectonics by two-

723 phase grain-damage and pinning. Physics of the Earth and Planetary Interiors 202-

$724 \quad 203,27-55$.

725 Berman, R.G., 1988. Internally-consistent thermodynamic data for minerals in the system

$726 \mathrm{Na}_{2} \mathrm{O}-\mathrm{K}_{2} \mathrm{O}-\mathrm{CaO}-\mathrm{MgO}-\mathrm{FeO}-\mathrm{Fe}_{2} \mathrm{O}_{3}-\mathrm{Al}_{2} \mathrm{O}_{3}-\mathrm{SiO}_{2}-\mathrm{TiO}_{2}-\mathrm{H}_{2} \mathrm{O}-\mathrm{CO}_{2}$. Journal of

727 Petrology 29, 455-522.

728 Bloomfield, J.P., Covey-Crump, S.J., 1993. Correlating mechanical data with

729 microstructural observations in deformation experiments on synthetic two-phase

$730 \quad$ aggregates. Journal of Structural Geology 15, 1007-1020.

731 Bons, P.D., Urai, J.L., 1994. Experimental deformation of two-phase rock analogues.

732 Materials Science and Engineering: A 175, 221-229.

733 Braun, J., Chéry, J., Poliakov, A., Mainprice, D., Vauchez, A., Tommasi, A., Daignières,

734 M., 1999. A simple parameterization of strain localization in the ductile regime due

735 to grain size reduction: A case study for olivine. Journal of Geophysical Research

$736 \quad 104,25167-25181$.

737 Brodie, K.H., Rutter, E.H., 1987. The role of transiently fine-grained reaction products in

738 syntectonic metamorphism: natural and experimental examples. Canadian Journal of

739 Earth Sciences 24, 556-564.

740 Bruhn, D.F., Olgaard, D.L., Dell'Angelo, L.N., 1999. Evidence for enhanced deformation

741 in two- phase rocks: Experiments on the rheology of calcite- anhydrite aggregates.

742 Journal of Geophysical Research 104, 707-724.

743 Bruijn, R., Skemer, P., 2014. Grain- size sensitive rheology of orthopyroxene.

744 Geophysical Research Letters 41, 1-10. 
745 Burnham, C.W., Holloway, J.R., Davis, N.F., 1969. The specific volume of water in the

746 range 1000 to 8900 bars, 20 to 900 C. American Journal of Science 267, 70-95.

747 De Bresser, J.H.P., Peach, C.J., Reijs, J.P.J., Spiers, C.J., 1998. On dynamic

748 recrystallization during solid state flow: effects of stress and temperature.

749 Geophysical Research Letters 25, 3457-3460.

750 De Bresser, J.H.P., Ter Heege, J.H., and Spiers, C.J., 2001. Grain size reduction by

751 dynamic recrystallization: can it result in major rheological weakening? International

752 Journal of Earth Sciences 90, 28-45.

753 Dell'Angelo, L., Tullis, J., 1996. Textural and mechanical evolution with progressive

754 strain in experimentally deformed aplite. Tectonophysics $256,57-82$.

755 den Brok, S.W.J., 1998. Effect of microcracking on pressure-solution strain rate: the $756 \quad$ Gratz grain boundary model. Geology 26, 915-918.

757 Derby, B., 1992. Dynamic recrystallization: the steady state grain size. Scripta

$758 \quad$ Metallurgica et Materialia 27, 1581-1586.

759 Dimanov, A., Dresen, G., 2005. Rheology of synthetic anorthite-diopside aggregates:

760 Implications for ductile shear zones. Journal of Geophysical Research 110, B07203, $761 \quad 1-24$.

762 Evans, B., Renner, J., Hirth, G., 2001. A few remarks on the kinetics of static grain 763 growth in rocks. International Journal of Earth Sciences 90, 80-103.

764 Farla, R., Karato, S., Cai, Z., 2013. Role of orthopyroxene in rheological weakening of 765 the lithosphere via dynamic recrystallization. Proceedings of the National Academy 766 of Sciences of the United States of America 110, 16355-16360. 
767 Farver, J., Yund, R., 2000. Silicon diffusion in a natural quartz aggregate: constraints on 768 solution-transfer diffusion creep. Tectonophysics 325, 193-205.

769 Fliervoet, T.F., White, S.H., Drury, M.R., 1997. Evidence for dominant grain-boundary

770 sliding deformation in greenschist- and amphibolite-grade polymineralic

771 ultramylonites from the Redbank Deformed Zone, Central Australia. Journal of

$772 \quad$ Structural Geology 19, 1495-1520.

773 Fournier, R.O., Potter, R.W., 1982. An equation correlating the solubility of quartz in

774 water from 25 to $900^{\circ} \mathrm{C}$ at pressures up to 10,000 bars. Geochimica et

$775 \quad$ Cosmochimica Acta 46, 1969-1973.

776 Freed, A.M., Hirth, G., Behn, M.D., 2012. Using short-term postseismic displacements to

777 infer the ambient deformation conditions of the upper mantle. Journal of

$778 \quad$ Geophysical Research 117, B01409, 1-15.

779 Gratier, J.-P., Renard, F., Labaume, P., 1999. How pressure solution creep and fracturing

780 processes interact in the upper crust to make it behave in both a brittle and viscous

781 manner. Journal of Structural Geology 21, 1189-1197.

782 Handy, M.R., 1994. Flow laws for rocks containing two non-linear viscous phases: a

783 phenomenological approach. Journal of Structural Geology 16, 287-301.

784 Hansen, L.N., Zimmerman, M.E., Kohlstedt, D.L., 2011. Grain boundary sliding in San

785 Carlos olivine: Flow law parameters and crystallographic-preferred orientation.

786 Journal of Geophysical Research 116, B08201, 1-16.

787 Herwegh, M., Berger, A., 2004. Deformation mechanisms in second phase affected

788 microstructures and their energy balance. Journal of Structural Geology 26, 1483-

$789 \quad 1498$.


790 Herwegh, M., Berger, A., Ebert, A., 2005. Grain coarsening maps: A new tool to predict 791 microfabric evolution of polymineralic rocks. Geology 33, 801.

792 Herwegh, M., Linckens, J., Ebert, A., Berger, A., Brodhag, S.H., 2011. The role of 793 second phases for controlling microstructural evolution in polymineralic rocks: A 794 review. Journal of Structural Geology 33, 1728-1750.

795 Hill, R., 1965. A self-consistent mechanics of composite materials. Journal of the 796 Mechanics and Physics of Solids 13, 213-222.

797 Hiraga, T., Tachibana, C., Ohashi, N., Sano, S., 2010. Grain growth systematics for 798 forsterite \pm enstatite aggregates: Effect of lithology on grain size in the upper mantle. 799 Earth and Planetary Science Letters 291, 10-20.

800 Hirth, G., Kohlstedt, D., 2003. Rheology of the upper mantle and the mantle wedge: a 801 view from the experimentalists. In: Inside the Subduction Factory. American 802 Geophysical Union, Geophysical Monograph 138, 83-105.

803 Hirth, G., Teyssier, C., Dunlap, W.J., 2001. An evaluation of quartzite flow laws based 804 on comparisons between experimentally and naturally deformed rocks. International $805 \quad$ Journal of Earth Sciences 90, 77-87.

806 Hirth, G., Tullis, J., 1992. Dislocation creep regimes in quartz aggregates. Journal of 807 Structural Geology 14, 145-160.

808 Holyoke, C.W., Tullis, J., 2006. Formation and maintenance of shear zones. Geology 34, $809 \quad 105-108$.

810 Humphreys, F.J., Hatherly, M., 2004. Recrystallization and Related Annealing 811 Phenomena, 2nd ed. Elsevier Science Ltd, Oxford, UK. 
812 Ji, S., Wang, Z., Wirth, R., 2001. Bulk flow strength of forsterite-enstatite composites as

813 a function of forsterite content. Tectonophysics 341, 69-93.

814 Ji, S., Zhao, P., 1994. Strength of two-phase rocks: a model based on fibre-loading

815 theory. Journal of Structural Geology 16, 253-262.

816 Ji, S., Zhao, P., Xia, B., 2003. Flow laws of multiphase materials and rocks from end-

817 member flow laws. Tectonophysics 370, 129-145.

818 Kenkmann, T., Dresen, G., 2002. Dislocation microstructure and phase distribution in a

819 lower crustal shear zone - an example from the Ivrea-Zone, Italy. International

$820 \quad$ Journal of Earth Sciences 91, 445-458.

821 Kilian, R., Heilbronner, R., Stünitz, H., 2011. Quartz grain size reduction in a granitoid

822 rock and the transition from dislocation to diffusion creep. Journal of Structural

$823 \quad$ Geology 33, 1265-1284.

824 Krabbendam, M., Urai, J.L., van Vliet, L.J., 2003. Grain size stabilisation by dispersed

825 graphite in a high-grade quartz mylonite: an example from Naxos (Greece). Journal

826 of Structural Geology 25, 855-866.

827 Kruse, R., Stünitz, H., 1999. Deformation mechanisms and phase distribution in mafic

828 high-temperature mylonites from the Jotun Nappe, southern Norway.

829 Tectonophysics 303, 223-249.

830 Langdon, T.G., 2006. Grain boundary sliding revisited: Developments in sliding over

831 four decades. Journal of Materials Science 41, 597-609.

832 Linckens, J., Bruijn, R.H.C., Skemer, P., 2014. Dynamic recrystallization and phase

833 mixing in experimentally deformed peridotite. Earth and Planetary Science Letters

$834 \quad 388,134-142$. 
835 Linckens, J., Herwegh, M., Müntener, O., Mercolli, I., 2011. Evolution of a

836 polymineralic mantle shear zone and the role of second phases in the localization of

837 deformation. Journal of Geophysical Research 116, B06210, 1-21.

838 McDonnell, R.D., Peach, C.J., Roermund, H., Spiers, C.J., 2000. Effect of varying

839 enstatite content on the deformation behavior of fine- grained synthetic peridotite

840 under wet conditions. Journal of Geophysical Research 105, 13535-13553.

841 Montési, L.G.J., 2007. A constitutive model for layer development in shear zones near

842 the brittle-ductile transition. Geophysical Research Letters 34, L08307, 1-5.

843 Montési, L.G.J., Hirth, G., 2003. Grain size evolution and the rheology of ductile shear

844 zones: from laboratory experiments to postseismic creep. Earth and Planetary

$845 \quad$ Science Letters 211, 97-110.

846 Muto, J., Hirth, G., Heilbronner, R., Tullis, J., 2011. Plastic anisotropy and fabric

847 evolution in sheared and recrystallized quartz single crystals. Journal of Geophysical

$848 \quad$ Research 116, B02206, 1-15.

849 Olgaard, D.L., 1990. The role of second phase in localizing deformation. Geological

$850 \quad$ Society London Special Publications 54, 175-181.

851 Platt, J.P., Behr, W.M., 2011a. Grainsize evolution in ductile shear zones: implications

852 for strain localization and the strength of the lithosphere. Journal of Structural

$853 \quad$ Geology 33, 537-550.

854 Platt, J.P., Behr, W.M., 2011b. Lithospheric shear zones as constant stress experiments. $855 \quad$ Geology 39, 127-130. 
856 Platt, J.P., Compagnoni, R., 1990. Alpine ductile deformation and metamorphism in a

857 Calabrian basement nappe (Aspromonte, south Italy). Eclogae Geologicae Helvetiae $858 \quad 83,41-58$.

859 Post, A., Tullis, J., 1999. A recrystallized grain size piezometer for experimentally 860 deformed feldspar aggregates. Tectonophysics 303, 159-173.

861 Rutter, E.H., Brodie, K.H., 1988. The role of tectonic grain size reduction in the 862 rheological stratification of the lithosphere. Geologische Rundschau 77, 295-308.

863 Rutter, E.H., Brodie, K.H., 2004. Experimental grain-size sensitive flow of hot-pressed

864 Brazilian quartz aggregates. Journal of Structural Geology 26, 2011-2024.

865 Rybacki, E., Gottschalk, M., Wirth, R., Dresen, G., 2006. Influence of water fugacity and

866 activation volume on the flow properties of fine-grained anorthite aggregates.

867 Journal of Geophysical Research 111, B03203, 1-16.

868 Schmid, S.M., 1982. Microfabric studies as indicators of deformation mechanisms and 869 flow laws operative in mountain building, in: Hsü, K.J. (Ed.), Mountain Building $870 \quad$ Processes. Academic Press, pp. 95-110.

871 Skemer, P., Karato, S., 2008. Sheared xenoliths revisited. Journal of Geophysical $872 \quad$ Research 113, B07205, 1-14.

873 Skemer, P., Karato, S.-I., 2007. Effects of solute segregation on the grain-growth kinetics 874 of orthopyroxene with implications for the deformation of the upper mantle. Physics 875 of the Earth and Planetary Interiors 164, 186-196.

876 Stipp, M., Stünitz, H., Heilbronner, R., Schmid, S.M., 2002a. Dynamic recrystallization 877 of quartz: correlation between natural and experimental conditions. Geological 878 Society of London Special Publication 200, 171-190. 
879 Stipp, M., Stünitz, H., Heilbronner, R., Schmid, S.M., 2002b. The eastern Tonale fault

$880 \quad$ zone: a 'natural laboratory' for crystal plastic deformation of quartz over a

881 temperature range from $250-700^{\circ} \mathrm{C}$. Journal of Structural Geology 24, 1861-1884.

882 Stipp, M., Tullis, J., 2003. The recrystallized grain size piezometer for quartz.

883 Geophysical Research Letters 30, 2088, 3-1 - 3-5.

884 Stipp, M., Tullis, J., Behrens, H., 2006. Effect of water on the dislocation creep

885 microstructure and flow stress of quartz and implications for the recrystallized grain

886 size piezometer. Journal of Geophysical Research 111, B04201, 1-19.

887 Stünitz, H., Fitz Gerald, J., 1993. Deformation of granitoids at low metamorphic grade.

888 II: Granular flow in albite-rich mylonites. Tectonophysics 221, 299-324.

889 Sundberg, M., Cooper, R.F., 2008. Crystallographic preferred orientation produced by

890 diffusional creep of harzburgite: Effects of chemical interactions among phases

891 during plastic flow. Journal of Geophysical Research 113, B12208, 1-16.

892 Takeda, Y.-T., 1998. Flow in rock modelled as multiphase continua: application to

893 polymineralic rocks. Journal of Structural Geology 20, 1569-1578.

894 Takeda, Y.-T., Griera, A., 2006. Rheological and kinematical responses to flow of two-

895 phase rocks. Tectonophysics 427, 95-113.

896 Tasaka, M., Hiraga, T., 2013. Influence of mineral fraction on the rheological properties

897 of forsterite + enstatite during grain-size-sensitive creep: 1. Grain size and grain

898 growth laws. Journal of Geophysical Research 118, 3970-3990.

899 Tasaka, M., Hiraga, T., Michibayashi, K., 2014. Influence of mineral fraction on the

900 rheological properties of forsterite+ enstatite during grain size sensitive creep: 3 . 
901 Application of grain growth and flow laws on peridotite ultramylonite. Journal of $902 \quad$ Geophysical Research 119, 840-857.

903 Tasaka, M., Hiraga, T., Zimmerman, M.E., 2013. Influence of mineral fraction on the 904 rheological properties of forsterite + enstatite during grain-size-sensitive creep: 2 .

905 Deformation experiments. Journal of Geophysical Research 118, 3991-4012.

906 Toy, V.G., Newman, J., Lamb, W., Tikoff, B., 2010. The role of pyroxenites in formation 907 of shear instabilities in the mantle: Evidence from an ultramafic ultramylonite, Twin 908 Sisters Massif, Washington. Journal of Petrology 51, 55-80.

909 Tullis, T.E., Horowitz, F.G., Tullis, J., 1991. Flow laws of polyphase aggregates from 910 end-member flow laws. Journal of Geophysical Research 96, 8081-8096.

911 Twiss, R.J., 1977. Theory and applicability of a recrystallized grain size paleopiezometer.

$912 \quad$ Pure and Applied Geophysics 115, 227-244.

913 van der Wal, D., Chopra, P., Drury, M., Fitz Gerald, J.D., 1993. Relationship between

914 dynamically recrystallized grain size and deformation conditions in experimentally

915 deformed olivine rocks. Geophysical Research Letters 20, 1479-1482.

916 Voorhees, P.W., 1992. Ostwald ripening of two-phase mixtures. Annual Review of $917 \quad$ Materials Science 22, 197-215.

918 Warren, J.M., Hirth, G., 2006. Grain size sensitive deformation mechanisms in naturally 919 deformed peridotites. Earth and Planetary Science Letters 248, 438-450.

920 Watson, E.B., Wark, D.A., 1997. Diffusion of dissolved $\mathrm{SiO}_{2}$ in $\mathrm{H}_{2} \mathrm{O}$ at $1 \mathrm{GPa}$, with 921 implications for mass transport in the crust and upper mantle. Contributions to 922 Mineralogy and Petrology 130, 66-80. 
923 White, S.H., Knipe, R.J., 1978. Transformation-and reaction-enhanced ductility in rocks.

924 Journal of the Geological Society, London 135, 513-516.

925 Xiao, X., 2002. Diffusion creep of anorthite-quartz aggregates. Journal of Geophysical

$926 \quad$ Research 107, 2279.

927 Yoon, K.Y., Chen, I.W., 1990. Superplastic flow of two-phase ceramics containing rigid

928 inclusions - zirconia/muillite composites. Journal of the American Ceramics Society

$929 \quad 73,1555-1565$.

930

931

\section{Figure and table captions}

933

934 Figure 1. Peridotite mylonite from the Pyrenees. Porphyroclast of orthopyroxene (Opx)

935 indicates primary grain size; the weak matrix flowing around it is a mixture of

936 dynamically recrystallized olivine (Ol) and orthopyroxene. Sample courtesy of Reinoud

937 Vissers; image courtesy of Whitney Behr.

938 Figure 2. a) Recrystallized tail on margin of plagioclase porphyroclast in granitoid

939 mylonite (PC32, Aspromonte massif, Calabria, Italy). Plagioclase (p) is recrystallizing by

940 subgrain rotation; recrystallized grains become separated by quartz (q). b) Quartz ribbons

941 in the same rock (top) deform by dislocation creep, and have a mean recrystallized grain

942 size of $70 \mu \mathrm{m}$; quartz-feldspar mixture in porphyroclast tails (bottom) have a grain size of $943 \sim 10 \mu \mathrm{m}$. 
944 Figure 3. a) Optical micrograph, b) electron backscatter image of the tail on a K-feldspar

945 porphyroclast in mylonitic gneiss (PW25, Whipple Mtns core complex, SE California).

946 Quartz was precipitated in cracks in the feldspar, and becomes mixed with recrystallized

947 feldspar in the tail. Grain size in the mixture is < $20 \mu \mathrm{m}$; in pure quartz ribbons the grain

948 size is $>100 \mu \mathrm{m}$.

949 Figure 4. a) Intimate mixing of fine-grained quartz (dark grey), albite (medium grey) and

950 K-feldspar (light grey) in tail of porphyroclast shown in Figure 3. b) EBSD map of K-

951 feldspar in the same area. Black areas are quartz. c) EBSD map of quartz in the same

952 area. Note dispersion of finely recrystallized quartz within feldspar (black).

953 Figure 5. a) Plagioclase porphyroclasts in granitoid mylonite (PC32, Aspromonte massif,

954 Calabria, Italy). Tails are a mixture of dynamically recrystallized quartz and plagioclase.

955 b) EBSD map of quartz in a tail (location outlined in a). Note relatively coarse-grained

956 quartz in ribbon on left (mean grain size $44 \mu \mathrm{m}$ ), compared with finer grained quartz

957 (mean grain size $15 \mu \mathrm{m}$ ) mixed with plagioclase (black) on right. c) EBSD map of

958 plagioclase, same area as b. Finely recrystallized plagioclase forms thin ribbons; larger

959 grains are partly recrystallized relicts from the porphyroclast at top. Mean grain size of

960 the fully recrystallized plagioclase is $13 \mu \mathrm{m}$.

961 Figure 6. a) CPO in quartz from the coarse-grained ribbon at left in Figure 5b. b) CPO in

962 quartz from the fine-grained quartz-feldspar mixture on the right in Figure 5b. c) CPO in

963 plagioclase from the fine-grained quartz-feldspar mixture on the right in Figure 5b. 
964 Figure 7. Cartoon illustration of the process of two-phase mixing in a granitoid rock,

965 based on the example shown in Fig. 2. Dynamic recrystallization of primary feldspar

966 creates an aggregate with a grain size controlled by the piezometric law for feldspar. The

967 aggregate starts to deform by grain-boundary sliding, and quartz diffuses into the spaces

968 between the grains. The end product has a grain size controlled by the feldspar, but the

969 dominant deformation mechanism is diffusion creep in quartz.

970 Figure 8. Strain-rate-grain-size (a), stress-strain-rate (b), and stress-T plots for

971 dislocation creep (Hirth et al., 2001) and three different pressure solution flow laws in

972 quartz (after Den Brok et al., 1998). See Appendix for the calculation method. Stress

973 values are differential stress.

974 Figure 9. a) Stress-grain-size deformation mechanism map for quartz, using the flow law

975 of Hirth et al. (2001) for dislocation creep, and the flow law of den Brok (1998) for thin-

976 film pressure solution creep. Piezometric line for quartz from Stipp and Tullis (2003),

$977 D_{\min }$ line from Platt and Behr (2011a). b) Stress-grain-size deformation mechanism map

978 for wet feldspar (maximum water fugacity for the quoted pressure and temperature),

979 using the flow laws for dislocation creep and diffusion creep of Rybacki et al. (2006).

980 Feldspar piezometric line from Post and Tullis (1999). c) Stress-grain-size deformation

981 mechanism map for wet granite/granitic ultramylonite, based on the composite flow laws

982 discussed in the text. Dynamic recrystallization and mixing at $45 \mathrm{MPa}$ differential stress

983 from $1 \mathrm{~mm}$ grain size (A) to $4 \mu \mathrm{m}$ on the felspar piezometric line (B) would result in an

984 increase of strain-rate by a factor of $\sim 5000$. Note that granite in the dislocation creep field

985 is several thousand times stronger than pure quartz, but in the diffusion creep field the 
986 strengths are fairly similar. d) Stress-temperature map for wet granitic ultramylonite, with

987 grain size calculated using the piezometric relationship for feldspar from Post and Tullis

988 (1999). Deformation is predicted to be in the diffusion creep field through the whole

989 range of stress and temperature. Note, however, that this map is likely to be unreliable at

990 high temperature, where water activity will be limited by partial melting. Stress values in

991 all maps are differential stress.

992 Figure 10. Orthopyroxene porphyroclast with dynamically recrystallized tail in a

993 xenolith from the Jagersfontein kimberlite, redrawn from an EBSD image in Bruijn and

994 Skemer (2014). Dynamically recrystallized pyroxene has a grain size of $\sim 50 \mu \mathrm{m}$, and

995 olivine $\sim 200 \mu \mathrm{m}$, both of which correspond to differential stress in the 20-30 MPa range

996 (Skemer and Karato, 2008), which suggests that the microstructure in both minerals has

997 not been significantly modified by grain growth. Note the decrease in recrytallized grain

998 size in the tail with distance from the porphyroclast, which suggests that a component of

999 dislocation creep and dynamic recrystallization continued to operate in the tail. Note also

1000 the scattered grains of olivine within the tail, suggesting diffusional mixing of the two

1001 phases.

1002 Figure 11 a) and b), stress-grain-size and stress-T maps for olivine; b) and c) for

1003 orthopyroxene; c) and d) for harzburgite with $70 \%$ olivine and $30 \%$ orthopyroxene, all at

$10041 \mathrm{GPa}$ and $1000^{\circ} \mathrm{C}$, based on the parameters in Table 1 and the composite flow laws

1005 discussed in the text. Olivine piezometer from van der Wal et al. (1993); orthopyroxene

1006 piezometer from Bruijn and Skemer (2014); $D_{\min }$ line for olivine calculated for a surface 
1007 energy of $1 \mathrm{~J} / \mathrm{m}^{2}$ (Tasaka and Hiraga, 2013) using Eqn 4. Water content in olivine is

1008 calculated from the fugacity using the formulation of Hirth and Kohlstedt (2003).

1009 


\section{Table and table caption}

\begin{tabular}{|l|c|c|c|c|c|c|c|}
\hline & $\begin{array}{c}\text { Qtz wet } \\
\text { dis creep }\end{array}$ & $\begin{array}{c}\text { Fsp wet } \\
\text { dis creep }\end{array}$ & $\begin{array}{c}\text { Fsp wet } \\
\text { diff creep }\end{array}$ & $\begin{array}{c}\text { Opx dis } \\
\text { creep }\end{array}$ & $\begin{array}{c}\text { Opx diff } \\
\text { creep }\end{array}$ & $\begin{array}{c}\text { Ol wet } \\
\text { dis creep }\end{array}$ & $\begin{array}{c}\text { Ol wet } \\
\text { diff creep }\end{array}$ \\
\hline$A \mathrm{~Pa}^{-\mathrm{n}} \mathrm{m}^{\mathrm{q}} \mathrm{s}^{-1}$ & $6.31 \mathrm{E}-36$ & $1.58 \mathrm{E}-18$ & $2.0 \mathrm{E}-25$ & $2.75 \mathrm{E}-9$ & $5.5 \mathrm{E}-17$ & $3.00 \mathrm{E}-20$ & $3.33 \mathrm{E}-19$ \\
\hline$Q(\mathrm{~J} / \mathrm{mole})$ & $1.35 \mathrm{E} 5$ & $3.45 \mathrm{E} 5$ & $1.59 \mathrm{E} 5$ & $6 \mathrm{E} 5$ & $3.8 \mathrm{E} 5$ & $4.8 \mathrm{E} 5$ & $3.35 \mathrm{E} 5$ \\
\hline$V\left(\mathrm{~m}^{3} / \mathrm{mole}\right)$ & & $38 \mathrm{E}-6$ & $38 \mathrm{E}-6$ & & & $1.1 \mathrm{E}-6$ & $4 \mathrm{E}-6$ \\
\hline$n$ & 4 & 3 & 1 & 2.9 & 1 & 3.5 & 1 \\
\hline$K \mathrm{~m} \mathrm{~Pa}^{-\mathrm{p}}$ & $8.899 \mathrm{E} 4$ & 0.5016 & & 17.3156 & & $1.4325 \mathrm{E} 6$ & \\
\hline$p$ & -1.26 & -0.66 & & -0.7645 & & -1.33 & \\
\hline$q$ & 0 & 0 & 3 & 0 & 3 & 0 & 3 \\
\hline$r$ & 1 & 1 & 1 & & & 1.2 & 1 \\
\hline ref & 1 & 2 & 2 & 3 & 4 & 5 & 5 \\
\hline
\end{tabular}

1011 Table 1. Flow law parameters for quartz (qtz), feldspar (fsp), orthopyroxene (opx) and

1012 olivine (ol). Dis creep, dislocation creep; diff creep, diffusion creep. A, prefactor; Q,

1013 activation energy; $V$, activation volume; $n$, stress exponent in flow law; $K$ constant for

1014 piezometric relation; $p$, exponent in piezometric relation; $q$, grain-size exponent in flow

1015 law; $r$, exponent for water content/fugacity; $k$, conductivity; $\kappa$, diffusivity; ref, reference.

1016 1, Hirth et al. (2001); 2, Post and Tullis (1999); Rybacki et al. (2006); 3, Bruijn and

1017 Skemer (2014); 4, Tasaka et al. (2013); Bruijn and Skemer (2014); 5, Hirth and Kohlstedt

1018 (2003); Freed et al. (2012). Water fugacity for quartz and feldspar flow laws was

1019 determined as a function of $\mathrm{P}$ and $\mathrm{T}$ from the fugacity calculator at

1020 http://www.geo.umn.edu/people/researchers/withe012/fugacity.htm (Pitzer and Sterner,

1021 1994). Water content for olivine flow law is calculated as ppm $\mathrm{H} / \mathrm{Si}$ from fugacity using

1022 the expression from Hirth and Kohlstedt (2003). The published values of the prefactors

1023 are based on these values. 


\begin{tabular}{|l|l|l|l|l|}
\hline sample & Qtz $\mu \mathrm{m}$ & Qtz MPa & QF mixtures $\mu \mathrm{m}$ & Fsp MPa \\
\hline PC32 & 44 & 24.3 & 13 & 8.9 \\
\hline PW25 & 100 & 12.7 & 20 & 4.6 \\
\hline Ref 1 & 110 & 11.7 & 15 & 7.2 \\
\hline Ref 2 & 50 & 22.0 & 9 & 15.5 \\
\hline Ref 2 & 40 & 26.2 & 6 & 28.7 \\
\hline Ref 2 & 30 & 32.9 & 5 & 37.8 \\
\hline
\end{tabular}

1026

1027 Table 2. Comparison of dynamically recrystallized grain-size in monomineralic quartz

1028 ribbons and in quartz-feldspar ultramylonite bands in the same sample, together with the

1029 differential stress inferred using the quartz and feldspar paleopiezometers respectively.

1030 PC32 and PW25, this paper; Ref 1, Kilian et al. (2011); Ref 2, Stünitz and Fitz Gerald

1031 (1993). 


\section{Platt Figure 1}

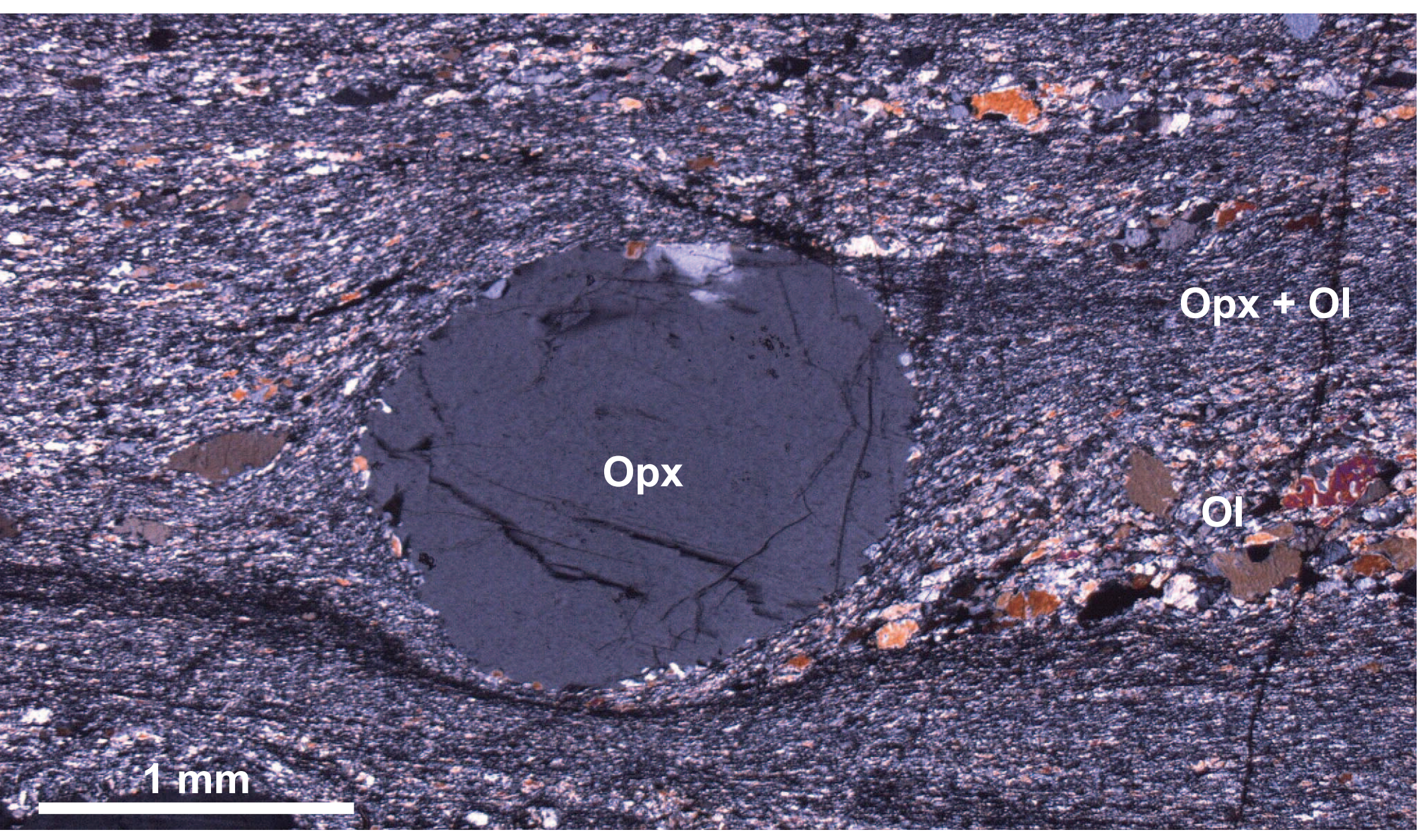


Platt Figure 3

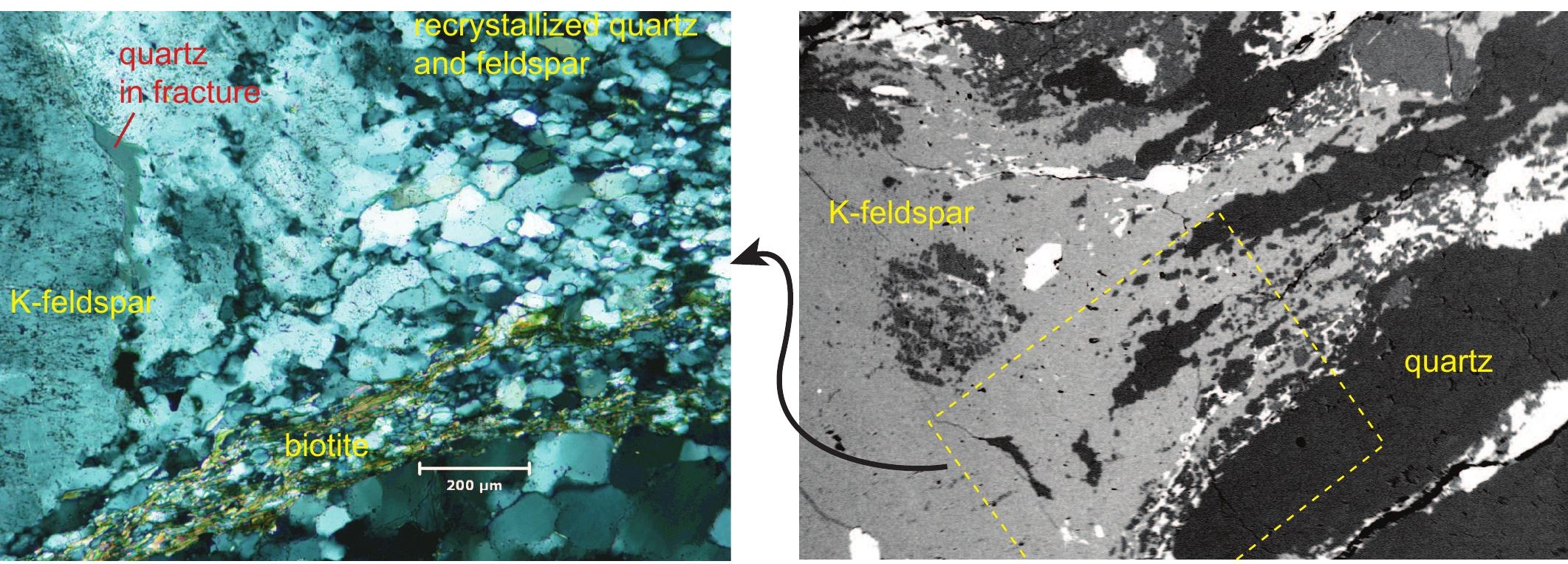




\section{Platt Figure 4}

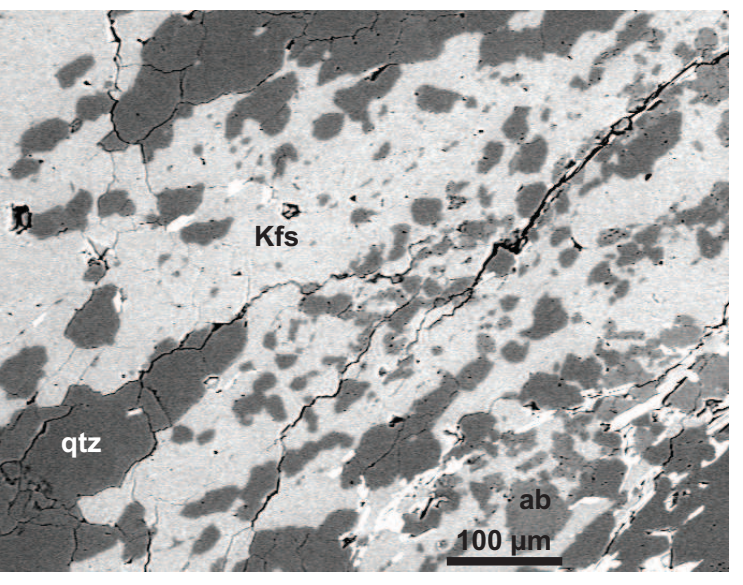

a

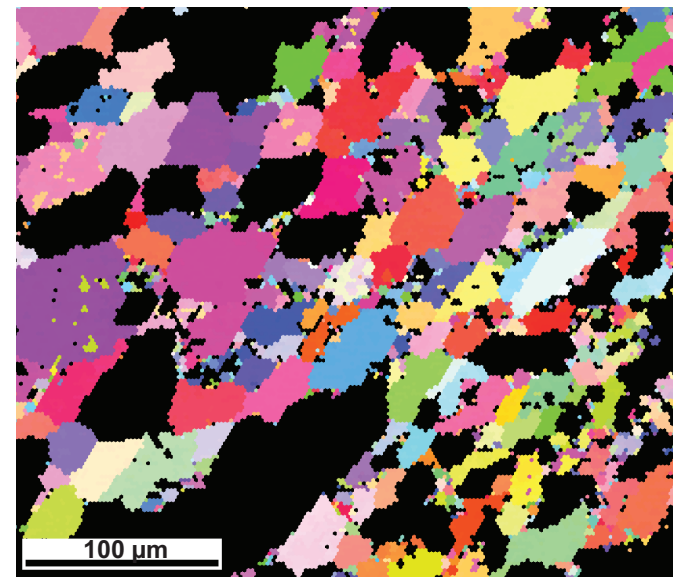

b

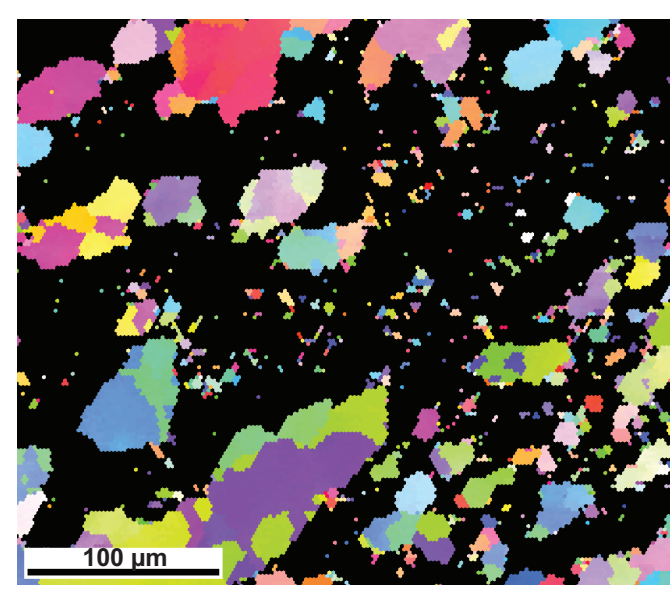

C 
Platt Figure 5
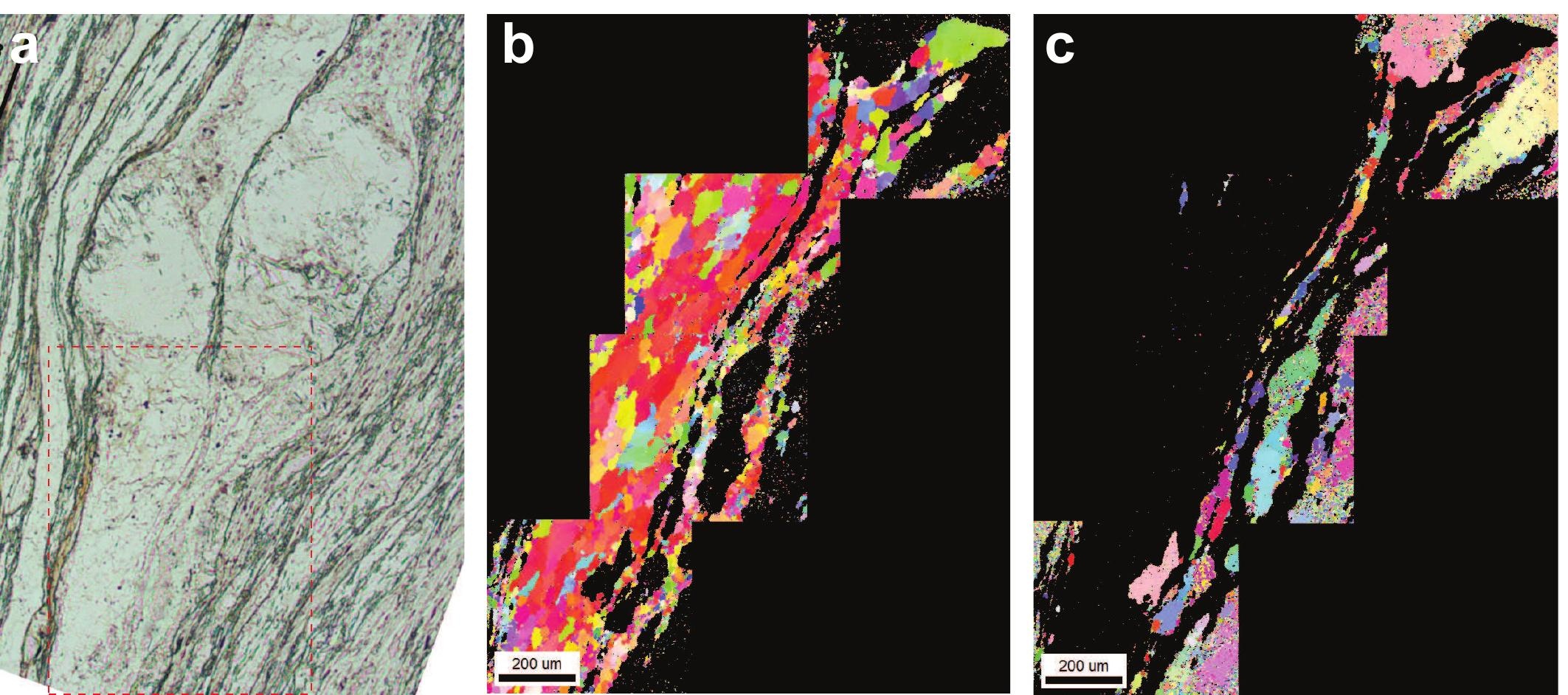
Platt Figure 6
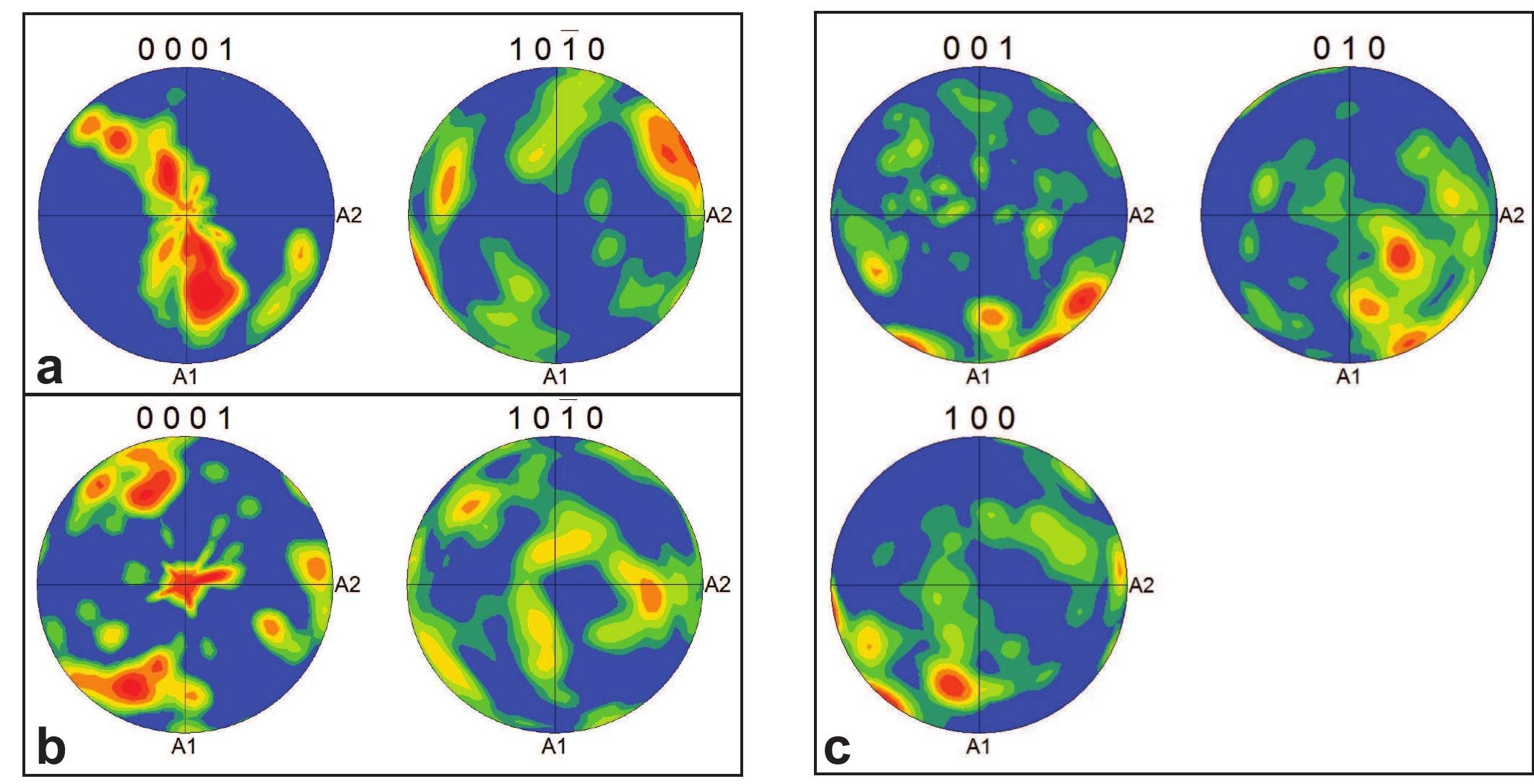
Platt Figure 7

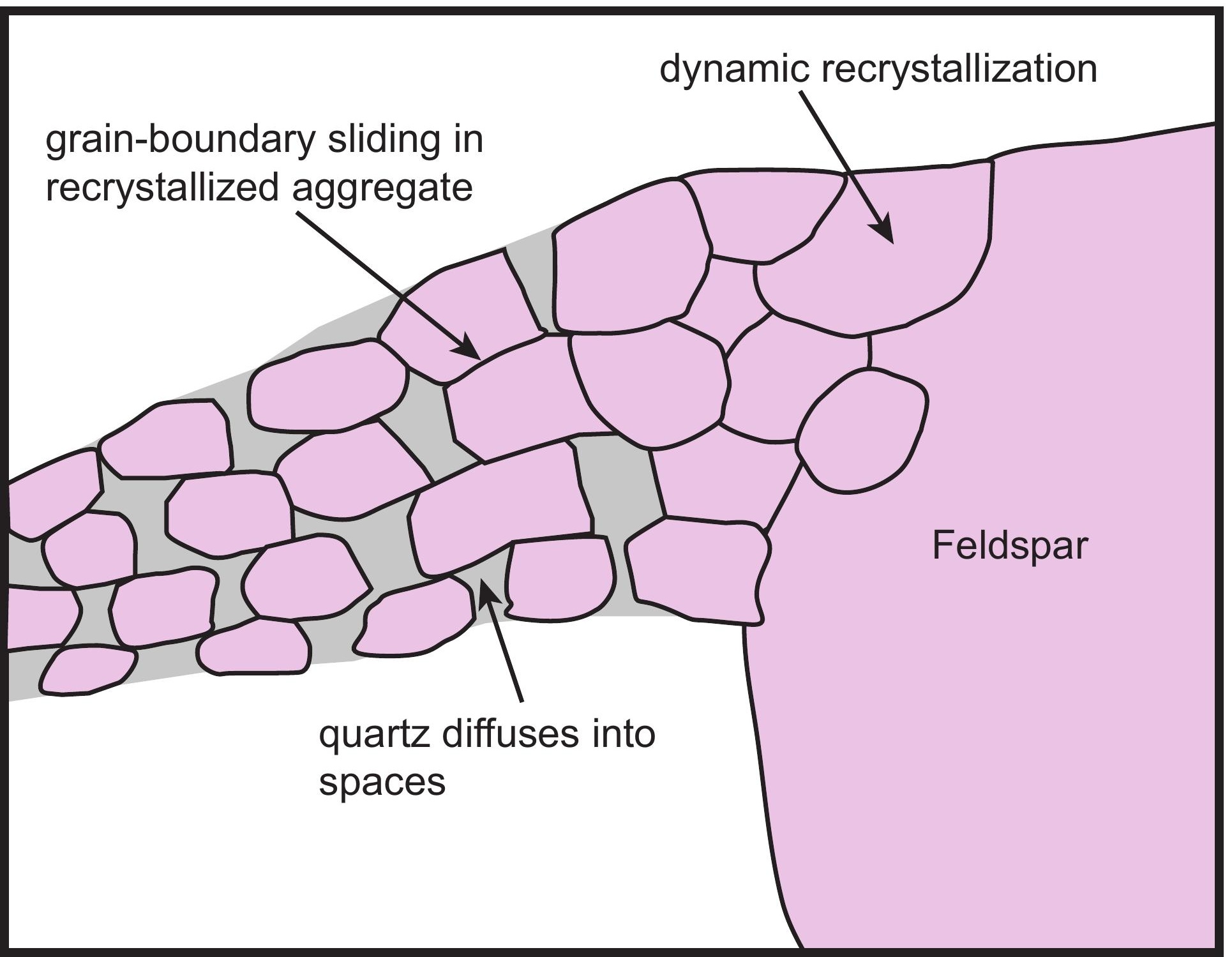




\section{Platt Figure 8}
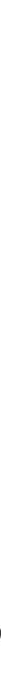
Platt Figure 10

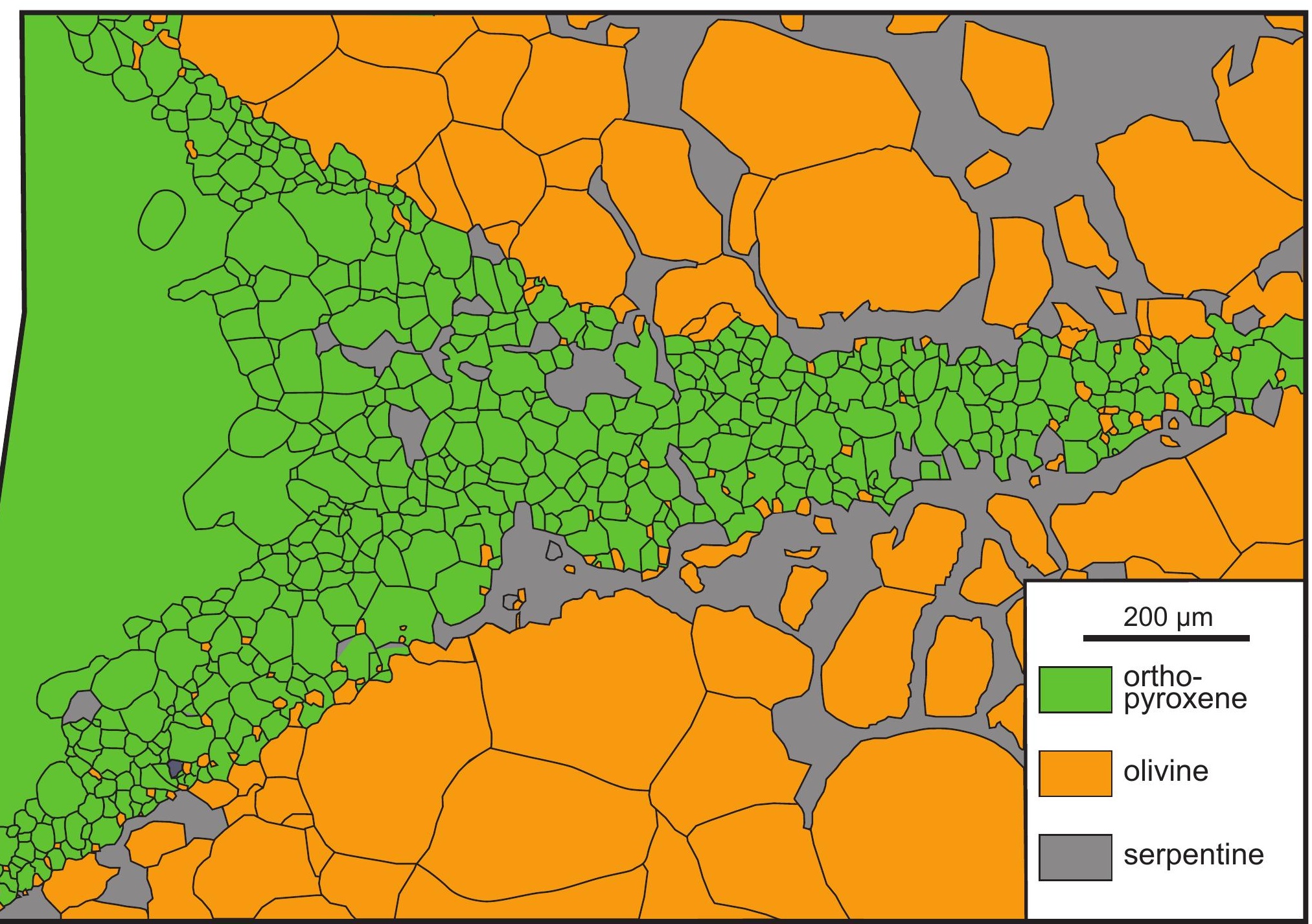



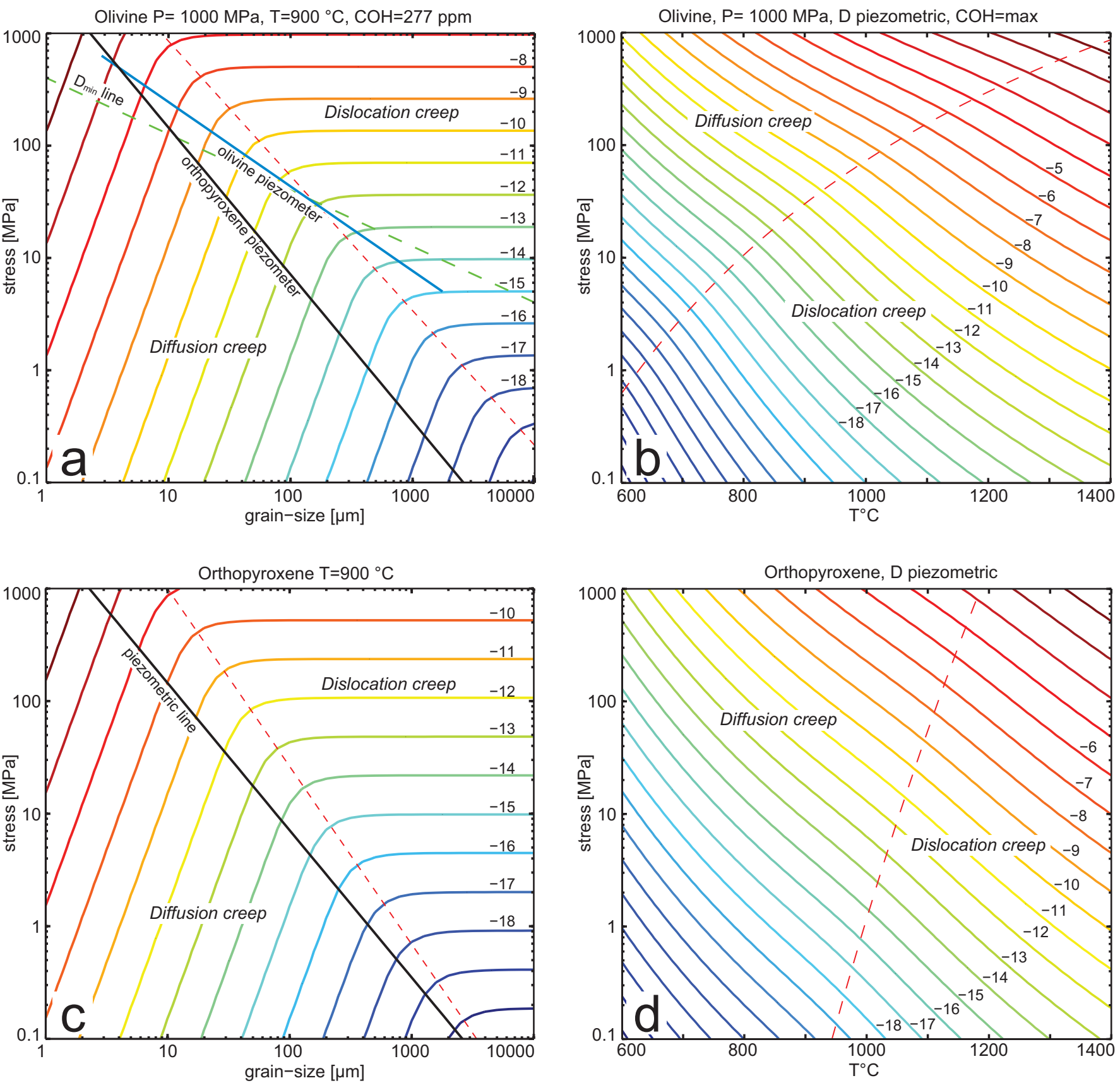

Peridotite-mylonite, $\mathrm{P}=1000 \mathrm{MPa}, \mathrm{T}=900{ }^{\circ} \mathrm{C}, \mathrm{COH}=277 \mathrm{ppm}$
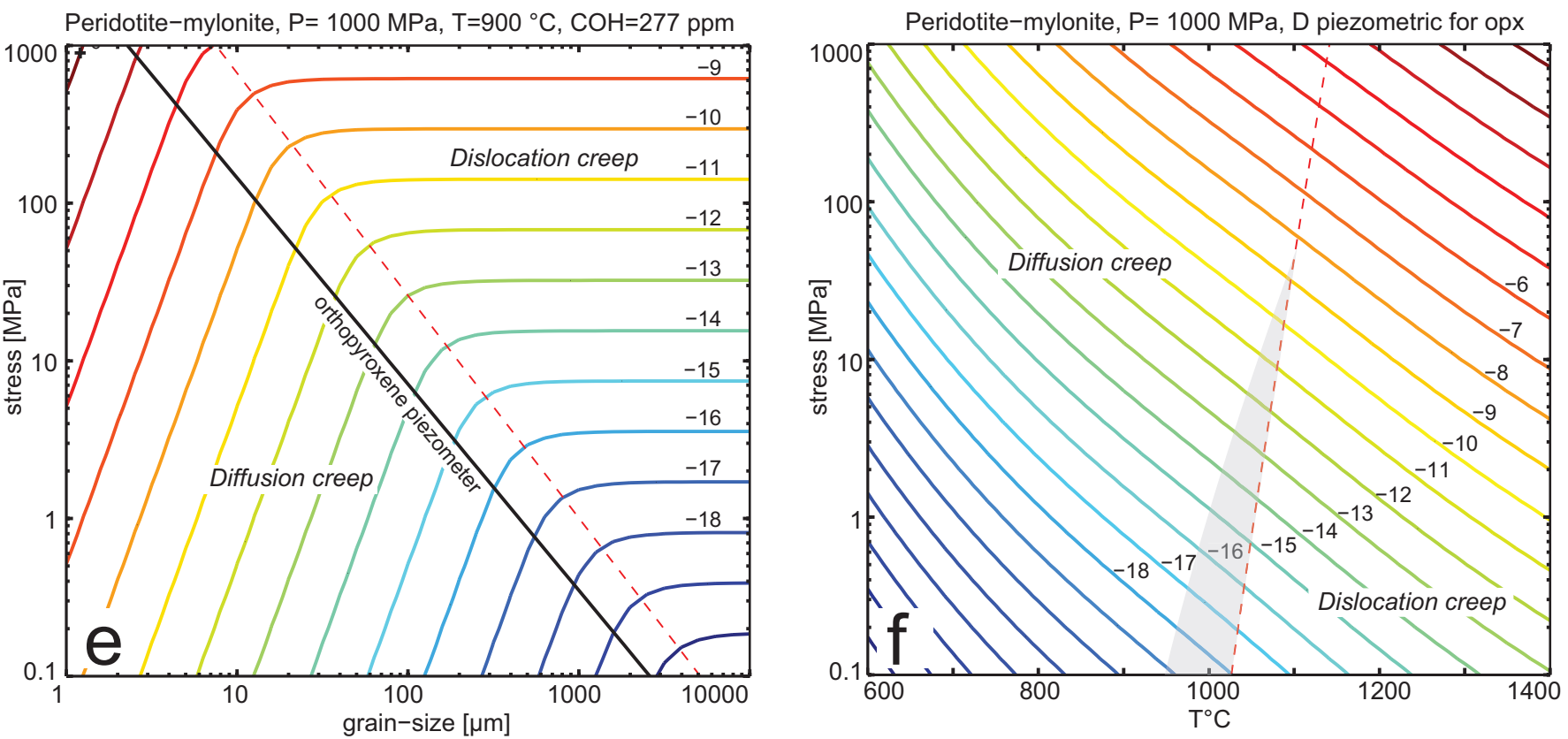